\title{
Indian Ocean impact on ENSO evolution 2014-2016 in a set of seasonal forecasting experiments
}

\author{
Michael Mayer ${ }^{1,2}$ [ $\cdot$ Magdalena Alonso Balmaseda ${ }^{1}$
}

Received: 17 June 2020 / Accepted: 24 December 2020 / Published online: 1 February 2021

(c) The Author(s) 2021

\begin{abstract}
This study investigates the influence of the anomalously warm Indian Ocean state on the unprecedentedly weak Indonesian Throughflow (ITF) and the unexpected evolution of El Niño-Southern Oscillation (ENSO) during 2014-2016. It uses 25-month-long coupled twin forecast experiments with modified Indian Ocean initial conditions sampling observed decadal variations. An unperturbed experiment initialized in Feb 2014 forecasts moderately warm ENSO conditions in year 1 and year 2 and an anomalously weak ITF throughout, which acts to keep tropical Pacific ocean heat content (OHC) anomalously high. Changing only the Indian Ocean to cooler 1997 conditions substantially alters the 2-year forecast of Tropical Pacific conditions. Differences include (i) increased probability of strong El Niño in 2014 and La Niña in 2015, (ii) significantly increased ITF transports and (iii), as a consequence, stronger Pacific ocean heat divergence and thus a reduction of Pacific $\mathrm{OHC}$ over the two years. The Indian Ocean's impact in year 1 is via the atmospheric bridge arising from altered Indian Ocean Dipole conditions. Effects of altered ITF and associated ocean heat divergence (oceanic tunnel) become apparent by year 2, including modified ENSO probabilities and Tropical Pacific OHC. A mirrored twin experiment starting from unperturbed 1997 conditions and several sensitivity experiments corroborate these findings. This work demonstrates the importance of the Indian Ocean's decadal variations on ENSO and highlights the previously underappreciated role of the oceanic tunnel. Results also indicate that, given the physical links between year-to-year ENSO variations, 2-year-long forecasts can provide additional guidance for interpretation of forecasted year-1 ENSO probabilities.
\end{abstract}

\section{Introduction}

In 2014 the scientific community and forecasters were expecting a major El Niño event, which was predicted by several seasonal forecasting systems (McPhaden 2015). Also, physical indicators like equatorial warm water content suggested that tropical Pacific conditions in 2014 were favourable for El Niño that year (Levine and McPhaden 2016). However, only moderately warm ENSO conditions materialized in 2014, but one year later in boreal winter 2015/16 one of the strongest El Niños on record occurred. Several studies investigated possible causes for the false alert in 2014 (Levine and McPhaden 2016; Zhu et al. 2016; Ineson et al. 2018; Puy et al. 2017; Hu and Fedorov 2017;

Michael Mayer

michael.mayer@ecmwf.int

1 Research Department, European Centre for Medium-Range Weather Forecasts, Shinfield Rd, Reading RG2 9AX, UK

2 Department of Meteorology and Geophysics, University of Vienna, Vienna, Austria
Dong and McPhaden 2018, among others). In addition, the 2015/16 El Niño deviated from the canonical picture of strong El Niño events (L'Heureux et al. 2017; Newman et al. 2018). In particular, Mayer et al. (2018) revealed the unusual energetics of that event. Despite warm conditions in the tropical Pacific in 2014 and especially 2015, its basinwide ocean heat content $(\mathrm{OHC})$ did not decrease during that period, which usually is the case during El Niño events (Mayer et al. 2014; Cheng et al. 2019). Also, in contrast with the persistent La Niña conditions following the strong 1997/98 El Niño event, there were no strong La Niña events in 2016-2018, which possibly was a result of the weak OHC loss in 2015/16.

Mayer et al. (2018) attributed the absence of heat discharge during 2015/16 to the exceptionally weak Indonesian Throughflow (ITF) transports during that time, much weaker than during other El Niño events, including 1997/98 (see their Fig. 2). They linked the anomalous heat transfer from the Indian to the Pacific Ocean to the anomalously warm Indian Ocean, as outlined below. 
To illustrate the different oceanic conditions in 1997 and 2014, Fig. 1 compares anomalous upper ocean heat content in the tropics in these two years. It is evident that conditions were similar in the equatorial Pacific, with warm anomalies in the west and cold anomalies in the east and a positive zonal mean OHC anomaly in the equatorial Pacific (visible in global zonal means in Fig. 1 despite partly opposing anomalies in the other basins). These conditions are representative of a recharged state susceptible for the subsequent development of an El Niño event (Jin 1997). In contrast to the equatorial Pacific, the Indian Ocean and the north-western part of the subtropical Pacific conditions in 2014 were quite different from those in 1997. These regions were much warmer than in 1997, which can be explained by the negative phase of the Pacific Decadal Oscillation (PDO; Newman et al. 2016) after 1998, which led to accumulation of warm waters in the Western Pacific and Indian Ocean, as well as enhanced ITF transports and rapid warming of the Indian Ocean during the so-called global warming hiatus period (Lee et al. 2015; Nieves et al. 2015).

The high Indian OHC in 2014 is also accompanied by anomalously high sea levels. During the onset of the 2015-16 El Niño the sea level in the Western Pacific decreased, leading to a reduced sea level gradient across the Maritime continent, which Mayer et al. (2018) used to dynamically explain the unprecedented weak ITF transports during 2015-16. Conversely, eastern Indian Ocean sea levels in 1997 were relatively low (as indicated by low OHC), leading to an enhanced sea level gradient across the Maritime continent and thus explaining the more moderate reduction of the ITF fluxes in 1997-98 despite the strength of the El Niño event.

An important and associated difference between the two periods is the behaviour of the Indian Ocean Dipole (IOD), a zonal mode in tropical Indian Ocean SST variability (Saji et al. 1999) that tends to co-vary and interact with ENSO (Cai et al. 2019). While there was a strong positive IOD event with strongly negative Eastern Indian Ocean SST anomalies in 1997 (explaining the low sea levels), there was only a very weak positive event associated with the 2015/16 El Niño. This can be linked to the anomalously warm Indian Ocean conditions in the latter period. The associated anomalously deep thermocline in the eastern Indian Ocean acted to reduce the sensitivity of SSTs to easterly wind anomalies arising from changes to the Walker circulation, the so-called atmospheric bridge (Annamalai et al. 2005). Conversely, the IOD can affect ENSO evolution via the atmospheric bridge during the same year (Annamalai et al. 2010; Luo et al. 2010) or potentially also in the subsequent year (Izumo et al. 2010). We note that the anomalously high OHC in the northwestern subtropical Pacific in 2014 (Fig. 1b) might have as well played a role in the arrested development of the 2014 warm event, as several authors have reported (e.g. Zhu et al. 2016), but in this paper we investigate the Indian-Pacific cross-basin interaction.

Here, using initialized two-year predictions, we further explore the role of the Indian Ocean in the tropical Pacific Ocean evolution during ENSO with a focus on the period 2014/02-2016/02. To isolate the role of the Indian Ocean and explore the mechanisms for its possible impact we carry out hindcasts with unperturbed ocean initial conditions (ICs) and hindcasts with modified Indian Ocean ICs, as described in Sect. 2. The findings are backed up with results from a second batch of similar experiments covering the period 1997/02-1999/02.

The paper is organized as follows. Section 2 describes the experiments and the analysis methodology. Results are presented in Sect. 3, which starts by evaluating the impact of the Indian Ocean on the atmosphere-ocean system and implications for the probability of extreme El Niño events (3.1).This also includes evaluation of the roles of the atmospheric bridge and oceanic tunnel, the relative importance of which remained elusive in earlier studies (Wang et al. 2019). Section 3.2 complements the traditional view provided in 3.1 with analysis of the energy budget. The aim of these diagnostics is twofold: (i) to check if the coupled forecasts are able to predict the energy budget evolution of the tropical Pacific, and if so (ii) to confirm the conclusions drawn

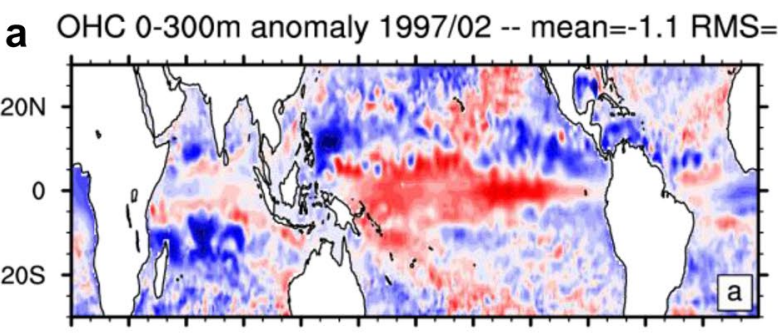

0 30E 60E 90E 120E150E 180150 M 20W90W 60W 30W

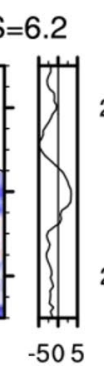

b OHC 0-300m anomaly 2014/02 -- mean $=1.4 \mathrm{RMS}=6.3$

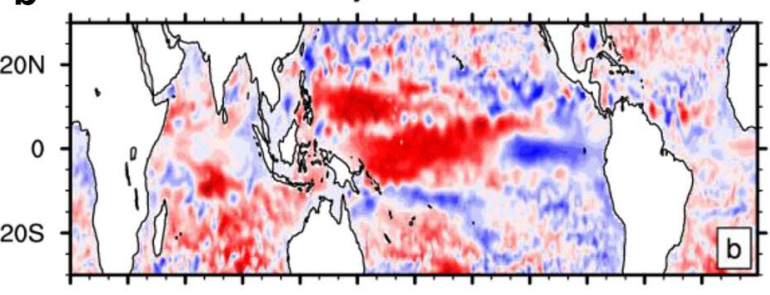

0 30E 60E 90E 120E150E $180150 \mathrm{~W} 20 \mathrm{~W} 90 \mathrm{~W} 60 \mathrm{~W} 30 \mathrm{~W}$

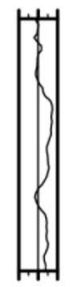

$-505$

$-28-24-20-16-12-8 \quad-4 \quad 0 \quad 4 \quad 8 \quad 1216202428 \times 10^{8} \mathrm{Jm}^{-2}$

Fig. 1 OHC anomalies in ORAS5 w.r.t 1992-2016 climatology in a 1997/02 and b 2014/02 
by Mayer et al. (2018), namely that the state of the Indian Ocean impacts the strength of the Indonesian Throughflow and, as a consequence, the evolution of the tropical Pacific heat budget. Finally, we contrast the effects of changed Indian Ocean background conditions (arising from changed initial sub-surface conditions) with intra-ensemble variability as drivers of the ITF and ENSO evolution (Sect. 3.3). Summary and conclusions follow in Sect. 4.

\section{Methods}

\subsection{Experimental set up}

We carried out a set of seasonal prediction experiments that use the same configuration as SEAS5, the current operational seasonal prediction system at the European Centre for Medium-Range Weather Forecasts (ECMWF; Johnson et al. 2019). SEAS5 uses ECMWF's Integrated Forecasting System (IFS) atmosphere model cycle 43r1 at T319 horizontal resolution with 91 vertical levels, coupled to the Nucleus for European Modelling of the Ocean (NEMO) 3.4.1 ocean model with 75 vertical levels and Louvain-la-Neuve Sea Ice Model 2 (LIM2), both running on a $14^{\circ}$ horizontal grid. Atmosphere and land are initialized from the European Interim Re-Analysis (ERA-Interim; Dee et al. 2011) and ocean and sea ice are initialized from Ocean Reanalysis System 5 (ORAS5; Zuo et al. 2019). Operational SEAS5 produces forecasts up to 13 months ahead, and Johnson et al. (2019) demonstrated that the system's ENSO predictions are skillful also at these long lead times. For example, anomaly correlation of forecasted Niño 3.4 anomalies with observations at lead month 13 is still $>0.6$ (average across four quarterly start dates). More details about ENSO in SEAS5 and the general performance of the system can be found in Johnson et al. (2019).

All experiments presented here are ran for 25 months and comprise 50 ensemble members each. They consist of two batches, as summarized in Table 1. The first batch is named Batch_14 and contains forecast experiments started in 2014/02. The reference forecast (REF_14) for Batch_14 is a reforecast over 2 years initialized from unmodified ocean initial conditions in 2014/02. Additionally, several experiments with modified ocean initial conditions were carried out. IndO_97 uses ocean initial conditions that are identical with those of REF_14 except for the Indian Ocean, where the initial conditions were replaced with those from 1997/02, with a transition zone to REF_14 initial conditions between 25 and 30S and in the Indonesian Throughflow region between 120 and 130E. This setup introduces spatial discontinuities, but inspection of results did not reveal any adjustments that may contaminate the results presented here. AllO_97 takes all ocean initial conditions from 1997/02 (but still atmospheric initial conditions from 2014/02, as REF_14). To investigate the role of the atmospheric bridge, we carried out an experiment, where only the upper Indian Ocean (upper $\sim 50 \mathrm{~m}$ ) has been replaced with 1997/02 conditions (IndO_97sfc). To sample the range of outcomes from the various observed Indian Ocean initial conditions, we carried out a 50-ensemble-member experiment with Indian Ocean initial conditions taken from the 25 years 1992/02 to 2016/02, with two members per year (IndO_scrambled). This experiment helps to assess how anomalous the Indian Ocean conditions in 1997 or 2014 were.

The second batch of experiments (Batch_97) consists of three experiments initialized in 1997/02. REF_97 is an unperturbed reforecast started in 1997/02. IndO_14 is the same as REF_97, but uses Indian Ocean initial conditions from 2014/02. The third experiment in Batch_97 uses ocean initial conditions from 2014/02 everywhere, but the same atmospheric initial conditions as REF_97 (AllO_14).

Since SEAS5 hindcasts only cover one year each, they cannot be used to estimate the second year bias of our experiments. Therefore, we carried out an additional experiment using ocean and atmosphere initial conditions taken from 1992/02 to 2016/02 globally, with two ensemble members
Table 1 Names and short description of all experiments used in the present study

\begin{tabular}{ll}
\hline & Batch_14: Experiments initialized in 2014/02 \\
\hline REF_14 & Reference forecast initialized on 2014/02 (50 members) \\
IndO_97 & As REF_14, but Indian Ocean ICs taken from 1997/02 (50 members) \\
AllO_97 & All ocean ICs taken from 1997/02 \\
IndO_97sfc & As REF_14, but upper 50 m of Indian Ocean ICs taken from 1997/02 \\
IndO_scrambled & As REF_14, but Indian Ocean ICs taken from 25 ICs 1992/02 to 2016/02 \\
& Batch_97: Experiments initialized in 1997/02 \\
REF_97 & Reference forecast initialized on 1997/02 \\
IndO_14 & As REF_14, but Indian Ocean ICs taken from 2014/02 \\
AllO_14 & All ocean ICs taken from 2014/02 \\
& Climatological baseline \\
AllO_scrambled & Ocean and atmosphere ICs for every member taken from 25 ICs 1992/02 to 2016/02 \\
\hline
\end{tabular}


per year, totalling 50 ensemble members (AllO_scrambled). This experiment samples the full range of different oceanic initial conditions during 1992-2016 and can thus be used to estimate the lead-time-dependent bias of our two-year-long forecasts which is used to debias forecast experiments, as in the operational system.

\subsection{Diagnostics}

\subsubsection{Energy budget diagnostics}

One important diagnostic used in this study are temporally accumulated changes to the heat budget of the tropical (30S-30N) Pacific, which reads as follows:

$\int \frac{\partial \mathrm{OHC}^{\prime}}{\partial \mathrm{t}} \mathrm{dt}=\mathrm{OHC}^{\prime}=\int \mathrm{F}_{\mathrm{S}}{ }^{\mathrm{d} t}-\int \nabla \cdot \mathrm{OHT}^{\prime} \mathrm{dt}$

In Eq. (1), $F_{S}$ denotes the net surface energy flux, and $-\nabla \cdot$ OHT the convergence of vertically integrated lateral ocean heat transport (computed from the sum of transports through the ITF and across $30 \mathrm{~N}$ and $30 \mathrm{~S}$ in the Pacific). All budget terms are averaged over the tropical Pacific, and the prime denotes anomalies relative to model climatology (as estimated from AllO_scrambled). We note that the heat budget residual is small, indicating that inaccuracies arising, e.g., from mixing across the lateral boundaries are negligible. The impact of changes in the ITF to the oceanic heat convergence cannot be unambiguously diagnosed, as there is a non-zero mass flux (Schauer and Beszczynska-Möller 2009; Trenberth and Zhang 2019). However, given that the ITF exports the warmest Pacific waters to the Indian Ocean, we consider the strength of ITF volume flux (defined positively eastward) a reasonable proxy of the ITF's contribution to oceanic heat convergence in the tropical Pacific: anomalously weak ITF volume flux (i.e. positive anomalies because of its climatologically westward flow) suggests anomalously strong Pacific ocean heat convergence and vice versa.

\subsubsection{Climate indices and definition of ENSO events}

We use two common SST indices for description of ENSO and the IOD, namely Niño 3.4 (N3.4; 5S-5 N; 170-120 W) and South-Eastern Tropical Indian Ocean (SETIO; averaged over 90-110 E, 0-10 S), respectively. The latter only covers the eastern pole of the IOD, but for this study we consider it a suitable proxy for the state of the IOD and associate negative (positive) SETIO SST anomalies with a positive (negative) IOD state.

To assess probabilities of ENSO states, we define four different categories according to the amplitude of the N3.4 anomalies (i.e., relative to AllO_scrambled): La Niña
(N3.4<- $0.5 \mathrm{~K})$, neutral conditions $(-0.5 \leq \mathrm{N} 3.4 \leq 0.5 \mathrm{~K})$, moderate El Niño $(\mathrm{N} 3.4>0.5 \mathrm{~K})$ and strong El Niño (N3.4>1.8 K). Definitions for moderate events follow definitions by National Oceanic and Atmospheric Administration's Climate Prediction Center, while our threshold for strong El Niños is higher than theirs $(1.5 \mathrm{~K})$ to focus on the extreme outcomes. The probability of occurrence of a given category is estimated by the number of ensemble members with values in that category normalized by the number of ensemble members. The uncertainty in the obtained probabilities is then estimated by bootstrapping with replacement. In this way, we create 1000 randomly sampled 50-members ensembles which we use to compute confidence intervals and assess the significance of probability differences between experiments.

\section{Results}

\subsection{Impact of Indian Ocean on the coupled tropical ocean-atmosphere system}

\subsubsection{Forecasting the evolution of the Indo-Pacific basin 2014-2016}

To set the scene for the forecasting experiments, we begin with evolution of relevant oceanic and atmospheric fields in the reference experiment REF_14 and observations depicted as longitude-time Hovmoeller diagrams in Fig. 2a-d, e-h, respectively. As several other models at the beginning of 2014, the REF_14 (which represents an extension of the operational SEAS5 forecast) ensemble mean SSTs (Fig. 2a) are indicative of an El Niño event peaking end of year 1 (Y1; see also Fig. 4a below for verification of N3.4). Consistent with anomalously warm eastern Pacific SSTs, REF_14 forecasts a positive 0-300 m OHC anomaly (Fig. 2b) in the eastern equatorial Pacific, anomalous westerly winds in the central Pacific (Fig. 2c) and changes to the velocity potential (Fig. 2d) that are consistent with changes to the Walker circulation typical of an El Niño event. The IOD mode is inactive in REF_14, in accordance with observations (see also Fig. 4b below for verification of SETIO). Interestingly, El Niño conditions persist into year 2 (Y2) of the forecast, with a slight reduction of the amplitude. The observed spatio-temporal evolution 2014-2016 was quite different. Moderately positive SST anomalies (Fig. 2e) present around the dateline in early 2014 were not amplified by the moderate westerly wind anomalies which quickly ceased in early summer 2014 (Fig. 2g), indicating a lack of coupling between SSTs and winds at that time (Dong and McPhaden 2018). The moderately positive SST anomalies lingered for the rest of 2014, before they got amplified in early 2015 , with strong wind feedbacks, and pronounced 

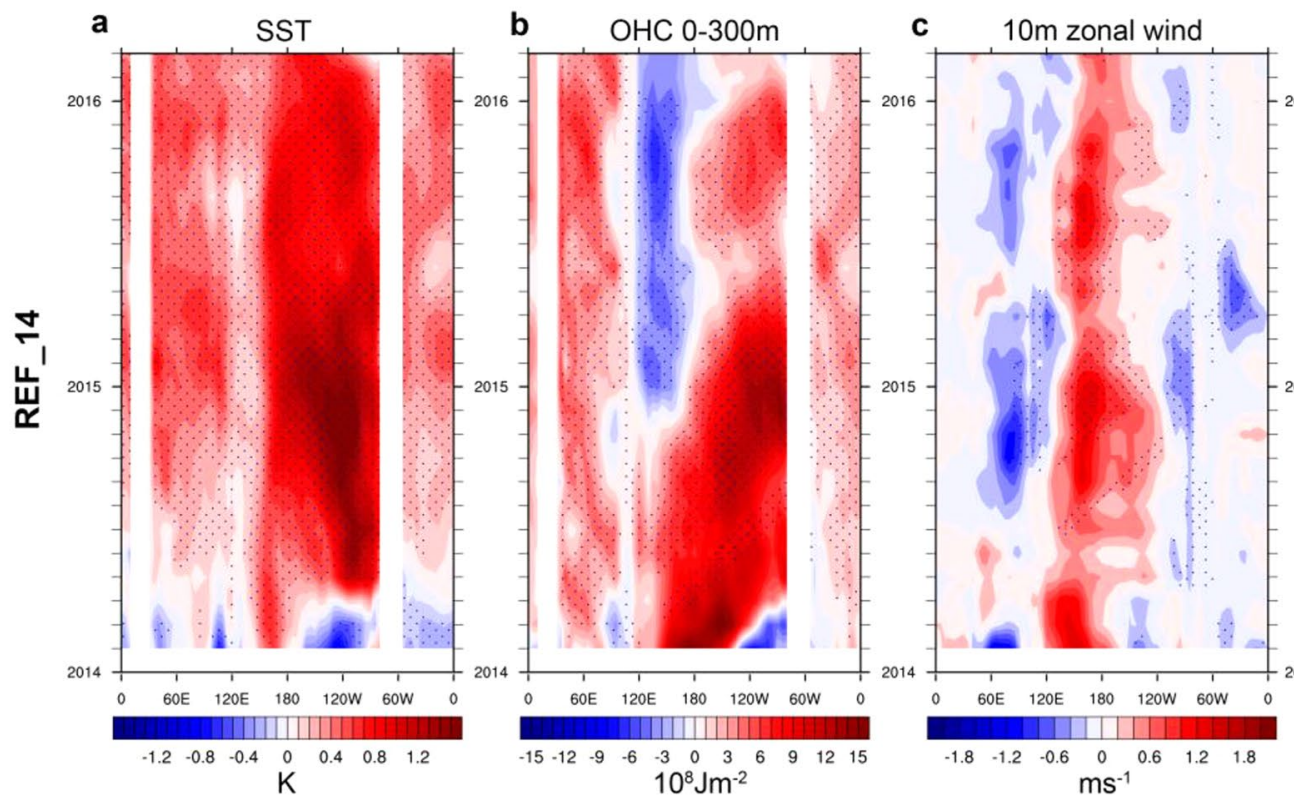

d $200 \mathrm{hPa}$ velocity potential
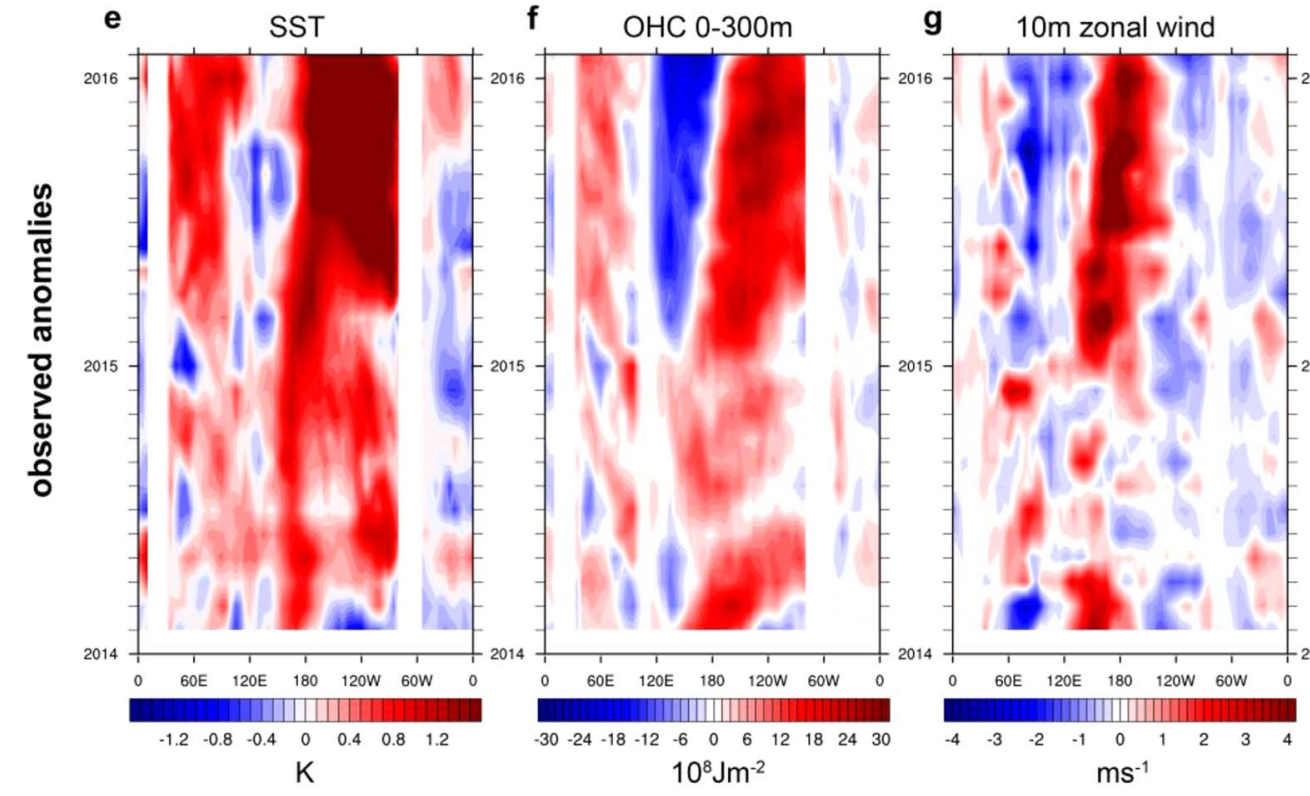

h $200 \mathrm{hPa}$ velocity potential

Fig. 2 Longitude-time Hovmoeller diagrams of anomalous equatorial (5 S-5 N) SST, 0-300 m OHC, $10 \mathrm{~m}$ zonal winds, and $200 \mathrm{hPa}$ velocity potential in a-d REF_14 w.r.t model climatology (estimated from AllO_ scrambled) and e-h observations (atmospheric variables from

signals in OHC (Fig. 2f) and velocity potential (Fig. 2h) along with the development of the strong El Niño 2015/16. We note that the poor performance of the REF_14 ensemble mean, which in principle does not represent a failure of the probabilistic forecast (see also Sect. 3.1.3), is not a limitation of this study, as we are primarily interested in changes relative to the reference. In particular, we note that SEAS5 is successful in discerning the very different evolutions during 2014-2016 and 1997-1999 (see supplementary material S1 for a comparison).
ERA-Interim, oceanic variables from ORAS5). Stippling denotes significant anomalies on the $95 \%$ confidence level. Note the different contour levels for the observational results to account for the stronger signals

\subsubsection{Role of Indian Ocean conditions}

We now turn to the experiments with modified initial conditions. Figure $3 \mathrm{a}-\mathrm{d}$ presents the evolution of differences between IndO_97 and REF_14 as longitude-time Hovmoeller diagrams of relevant ocean and atmospheric variables (snapshots of differences in OHC between these two experiments can be seen in S2). We discuss IndO_97 along with IndO_97sfc (displayed in Fig. 3e-h), which has the same Indian Ocean conditions in the upper $50 \mathrm{~m}$, but the same 

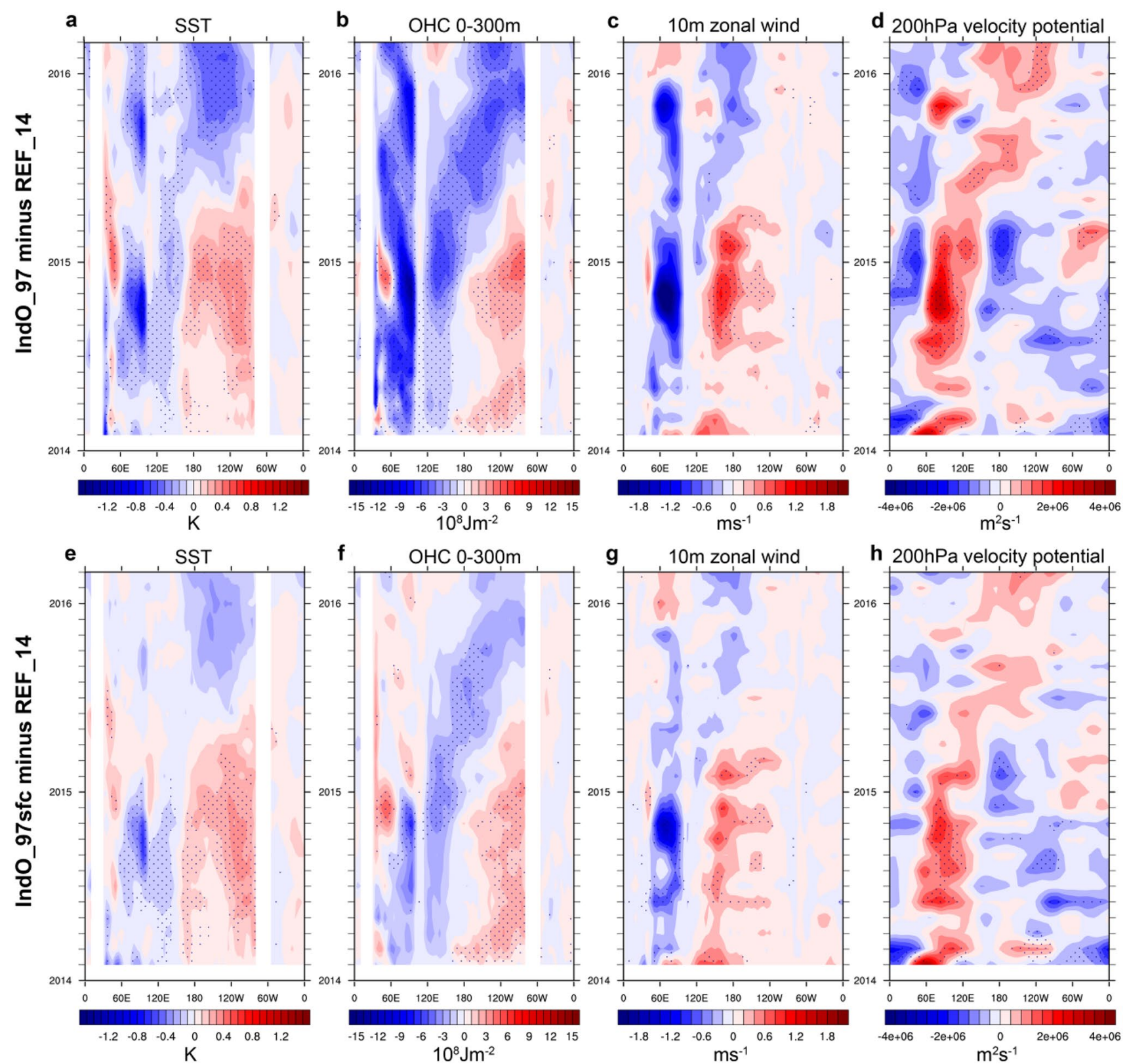

h $200 \mathrm{hPa}$ velocity potential

Fig. 3 Longitude-time Hovmoeller diagrams of the differences in equatorial (5 S-5 N) SST, 0-300 m OHC, $10 \mathrm{~m}$ zonal winds, and velocity potential (upper row) between IndO_97 and REF_14 and (lower row) between IndO_97sfc and REF_14. Stippling denotes significant differences on the $95 \%$ confidence level

colder SSTs (Fig. 3a) and lower OHC (Fig. 3b) in IndO_97 relative to REF_14, reflecting the cooler Indian Ocean state in 1997 compared to 2014. More pronounced differences at short lead times can be seen in zonal winds, which are more westerly in IndO_97 in the Western Pacific between 120 and 180 E during lead months one and two (Fig. 3c). In the Indian Ocean, easterly wind anomalies are present in IndO_97 compared to REF_14 already from lead month 1 (Fig. 3c), which is related to a decrease (increase) in precipitation over the warm pool (western Indian Ocean; not 

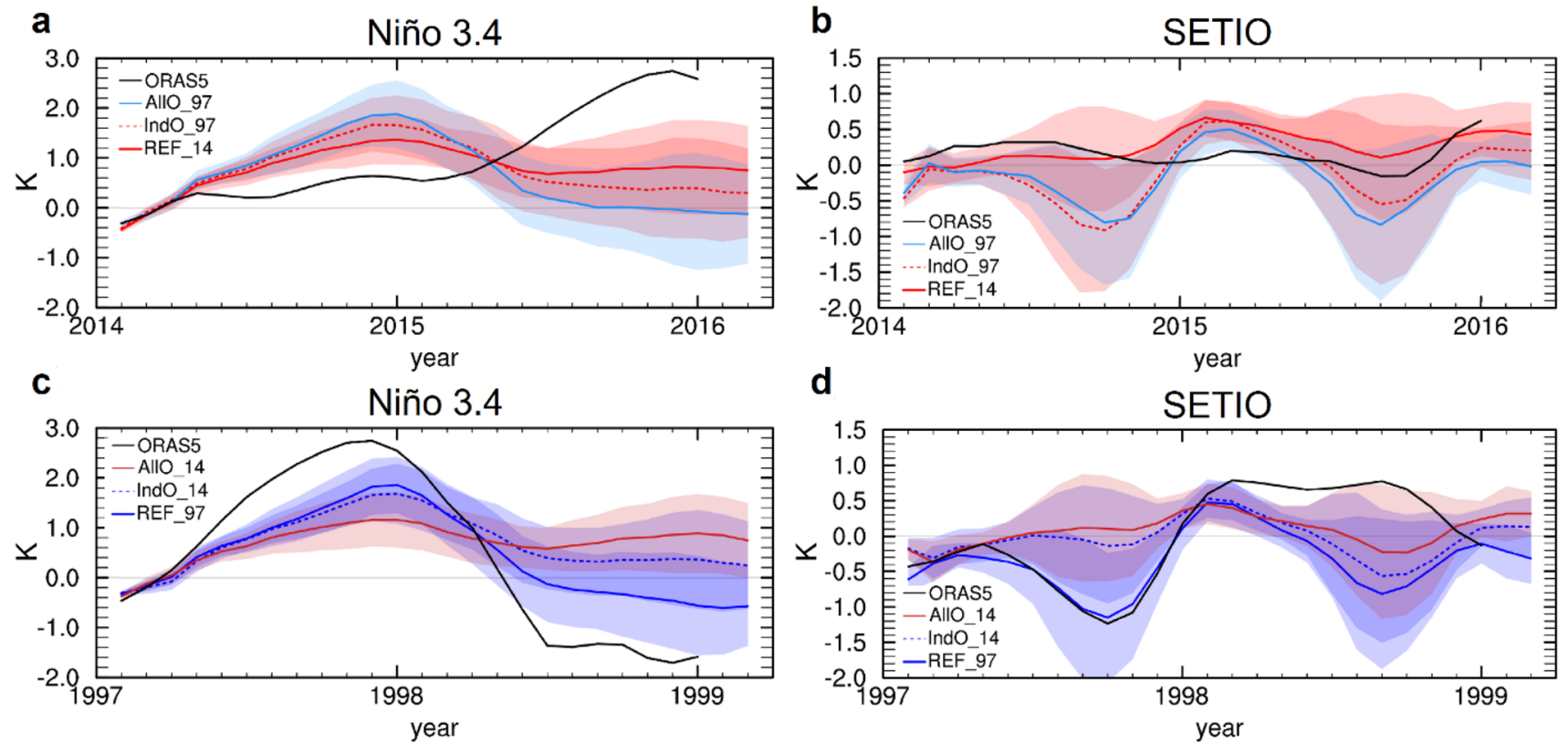

Fig. 4 a Niño 3.4 and b SETIO SST anomalies in Batch_14; c Niño 3.4 and d SETIO SST anomalies in Batch_97. Anomalies are w.r.t model climatology (estimated from AllO_scrambled). The shading represents ensemble spread $( \pm 1 \sigma)$. Results from ORAS5 are shown as well

shown). This initial difference in the winds is a result of the changed SST distribution in the initial conditions (not shown). For the further development (described below) of SSTs and zonal winds it is difficult to distinguish cause and effect, but zonal winds and SSTs certainly feed back on each other. We also note that the differences in $10 \mathrm{~m}$ zonal wind are consistent with differences in the $200 \mathrm{hPa}$ velocity potential (Fig. 3d), which indicate associated changes in upper level divergence as an eastward propagating dipole originating in the Indian Ocean.

The stronger westerly winds in the Western Pacific from lead month 1 (Fig. 3c) trigger warm equatorial Pacific SST anomalies relative to REF_14 (Fig. 3a), which then slowly propagate eastward during Y1. There is also the signature of an eastward propagating downwelling Kelvin wave in $\mathrm{OHC}$ (Fig. 3b) in the equatorial Pacific during the first few lead months. Warm SST anomalies appear also in the eastern equatorial Pacific once that wave reaches South America around lead month $2-3$, and start propagating slowly westward.

Equatorial Pacific SST evolution of IndO_97sfe in Y1 is similar to that of IndO_97 (compare Fig. 3a, e), with only slightly less pronounced eastward propagating anomalies associated with the warm pool displacement. These changes are consistent with westerly wind anomalies during the first two lead months (compare Fig. 3c, g). Over the Indian Ocean, differences in atmospheric variables $(10 \mathrm{~m}$ wind and $200 \mathrm{hPa}$ velocity potential) over the first $2-3$ months also resemble the behaviour of IndO_97.
Amplification and mature phase A shallower Indian Ocean thermocline in 1997 compared to 2014, as suggested by lower OHC, also means that the eastern Indian Ocean is more sensitive to the Bjerknes feedback associated with the onset of IOD events (Annamalai et al. 2005; Ummenhofer et al. 2017). Indeed, IndO_97 produces much colder SSTs in the eastern Indian Ocean by boreal fall of 2014 (Fig. 3a), indicative of a positive IOD event and probably triggered by the easterly wind anomalies in lead month 1.

Once the negative SST anomalies in the eastern Indian Ocean are developed in IndO_97 relative to REF_14 (boreal fall 2014), the weakly positive westerly wind signal in the central Pacific gets enhanced, consistent with changes in the $200 \mathrm{hPa}$ velocity potential around that time (Fig. 3c, d, respectively). Along with this development, warmer SSTs spread eastward along the equatorial Pacific, pushing the edge of the warm pool, and leading to a warmer ENSO state in IndO_97 in winter 2014/15. At the same time, negative anomalies in $\mathrm{OHC}$ are much enhanced in the western Pacific (Fig. 3b).

By end of 2014, experiment IndO_97sfc shows distinctive differences w.r.t. IndO_97: The positive IOD signal is much weaker in IndO_97sfc, confirming the suspicion that it is the shallower thermocline in IndO_97 that represented more favourable conditions for the IOD event in fall 2014. IndO_97sfc exhibits a qualitatively similar, but much weaker subsurface signal in the Pacific after Y1. Nevertheless, eastern Pacific SSTs are similarly warm relative to REF_14 (Fig. 3f). 
Demise of warming and switch to cold conditions In Y2 of IndO_97, the negative OHC anomalies in the western Pacific basin slowly propagate eastward (more slowly than free Kelvin waves), as described by Zhou et al. (2015), and almost all equatorial Pacific is in a colder state than in REF_14 from spring 2015 onward (Fig. 3b). SST differences in the equatorial Pacific become negative as well (Fig. 3a), indicating an ENSO state shifted more towards La Niña in IndO_97 end of 2015.

Difference patterns in IndO_97sfc in Y2 exhibit reduced magnitude compared to those in IndO_97 (compare upper and lower rows of Fig. 3). This suggests that the Indian Ocean subsurface is important for the development of the IOD event simulated by IndO_97 in Y1 and the subsequent development of the equatorial Pacific in $\mathrm{Y} 2$ of the forecasts. As will be seen in Sect. 3.2, the very different behaviour of the ITF in IndO_97 and IndO_97sfc suggests that the oceanic tunnel plays a non-negligible role for the state of the Pacific in Y2.

\subsubsection{Impact on climate indices}

The evolution of Niño 3.4 ensemble mean and spread $( \pm 1 \sigma)$ in the three main experiments of Batch_14 as well as in observations is shown in Fig. 4a. The observations exhibit a weak warming in 2014/15, followed by a strong El Niño event in 2015/16, while in the ensemble mean of REF_14 the sequence of events is the opposite, with a clear overestimation (underestimation) of the warming in Y1 (Y2). However, the observed outcome was just encompassed by the range of the full REF_14 ensemble, as can be seen in the forecast plumes in supplementary material S3. Importantly, the REF_14 ensemble mean correctly predicted the absence of La Niña in 2015/16 despite the warm ENSO conditions in 2014/15. IndO_97 simulates warmer (colder) ENSO conditions than REF_14 during Y1 (Y2). It thus exhibits enhanced ENSO variability with stronger amplitude. AllO_97 is even warmer (colder) than IndO_97 during Y1 (Y2).

The forecast performance for the SETIO are shown in Fig. 4b. REF_14 correctly predicts neutral SETIO anomalies in $\mathrm{Y} 1$ and $\mathrm{Y} 2$, indicative of non-occurrence of an IOD event. This is changed in IndO_97 and AllO_97, which predict a positive IOD event in Y1. The evolution of AllO_97 is consistent with the quite successful prediction of the observed evolution of the Indo-Pacific during 1997-1999 by SEAS5 (see Fig. 4c, d, respectively), with strongly positive Niño 3.4 anomalies in $\mathrm{Y} 1$ and weakly negative anomalies in $\mathrm{Y} 2$. In the context of this study it is noteworthy that Niño 3.4 anomalies in IndO_97 are closer to those of AllO_97 than to those of REF_14, despite the identical Pacific ICs in IndO_97 and REF_14.

Results from the Batch_97 forecasts are presented in Fig. 4c, d. REF_97 successfully predicts strongly positive
Niño 3.4 anomalies (Fig. 4c) and a positive IOD event (Fig. 4d) in Y1 and negative Niño 3.4 anomalies in Y2. Swapping the Indian Ocean conditions with those of 2014 (experiment IndO_14), reduces slightly the peak warm Niño 3.4 values in Y1, and more strikingly, it reduces the chances of a cold event in the second year. Moreover, the SETIO anomaly is neutral throughout the forecast, despite the remote forcing from the strong El Niño event in this experiment (Fig. 4d), which demonstrates the importance of the Indian Ocean conditions for the development of the 1997 IOD event. AllO_14 behaves very similarly to REF_14, confirming that the source of ENSO predictability mainly lies in the ocean.

\subsubsection{Influence on the probability of extreme ENSO events}

In the previous section we found a profound impact of the Indian Ocean state on the Indo-Pacific atmosphere-ocean system, focussing on the influence on the ensemble mean forecasts. In this section, we analyse in more detail the influence of the Indian Ocean state on the occurrence, intensity and predictability of ENSO events in our experiments.

Figure 5 shows ensemble-derived probabilities of occurrence of La Niña, neutral conditions, moderate El Niño and strong El Niño (see Sect. 2.2.2 for definitions) in relevant Batch_14 and Batch_97 experiments in Y1 and Y2. REF_14 (Fig. 5a) predicts at least moderate El Niño conditions in Y1 with a $94 \%$ probability and El Niño in Y2 with a $58 \%$ probability. Interestingly, the probabilities of a strong warm event do not change substantially between Y1 and Y2 (18\% and $16 \%$ respectively). Probabilities for La Niña are $0 \%$ in $\mathrm{Y} 1$ and $4 \%$ in Y2. Probabilities in REF_14 and AllO_14 are very similar (not shown).

Changing the Indian Ocean initial conditions has a substantial impact on the ENSO probabilities. In IndO_97 (Fig. 5c), the odds for a strong El Niño event in Y1 are more than doubled compared to REF_14 (44\%; a significant increase w.r.t. REF_14), and there is a $100 \%$ probability that there is at least a moderate El Niño in Y1. Also in contrast with REF_14, the probability of warm conditions in Y2 decreases and instead, there is now an $18 \%$ probability for La Niña in Y2. This result suggests that stronger tropical Pacific OHC discharge (as occurs in IndO_97, see Fig. 3b) yields higher probabilities for La Niña in the subsequent year. Interestingly, experiment IndO_97sfc (Fig. 5e) exhibits very similar probabilities of El Niño in Y1 and La Niña in $\mathrm{Y} 2$ as experiment IndO_97, indicating the importance of the Indian ocean SST anomalies and associated atmospheric bridge on the occurrence of strong El Niño in Y1, and the increased probability of a cold event in $\mathrm{Y} 2$ following a strong warm event in Y1. The only significant difference between IndO_97sfc and IndO_97 is the increased probability of a moderately warm event in Y2 (48\% in IndO_97sfc 


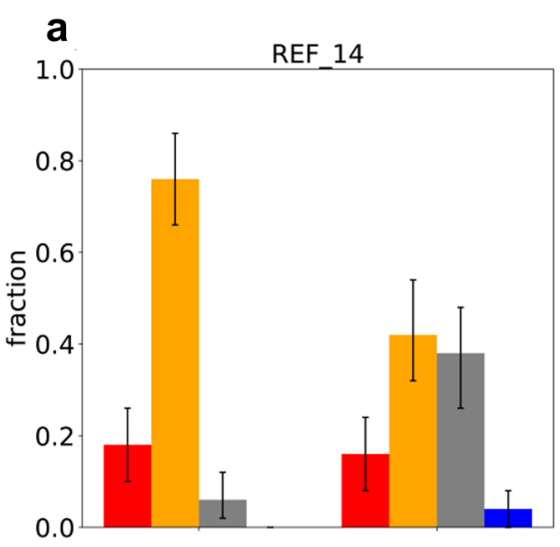

Y1
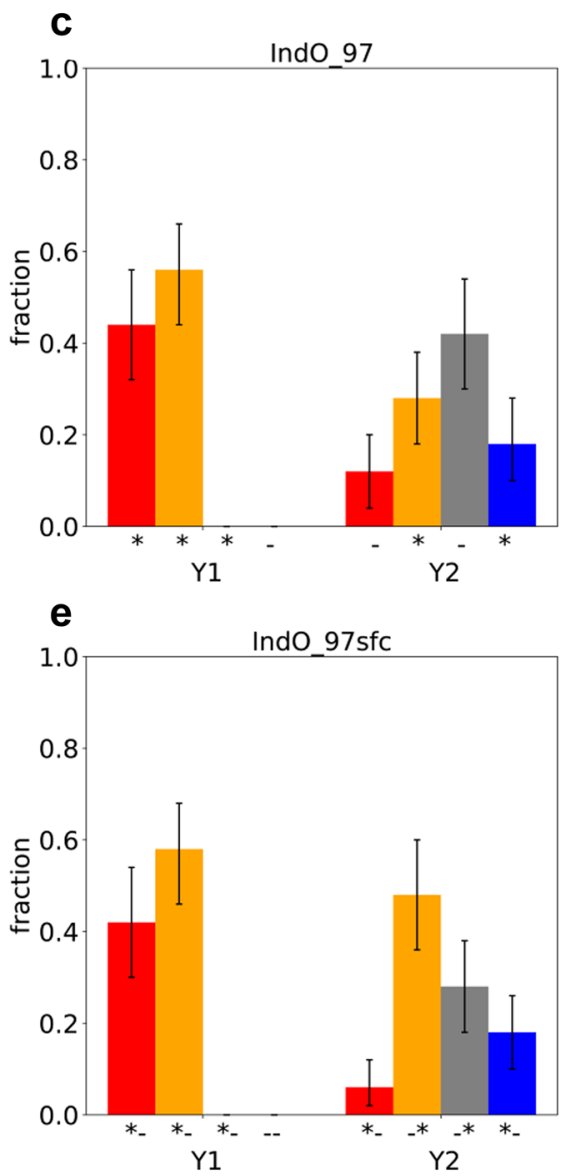
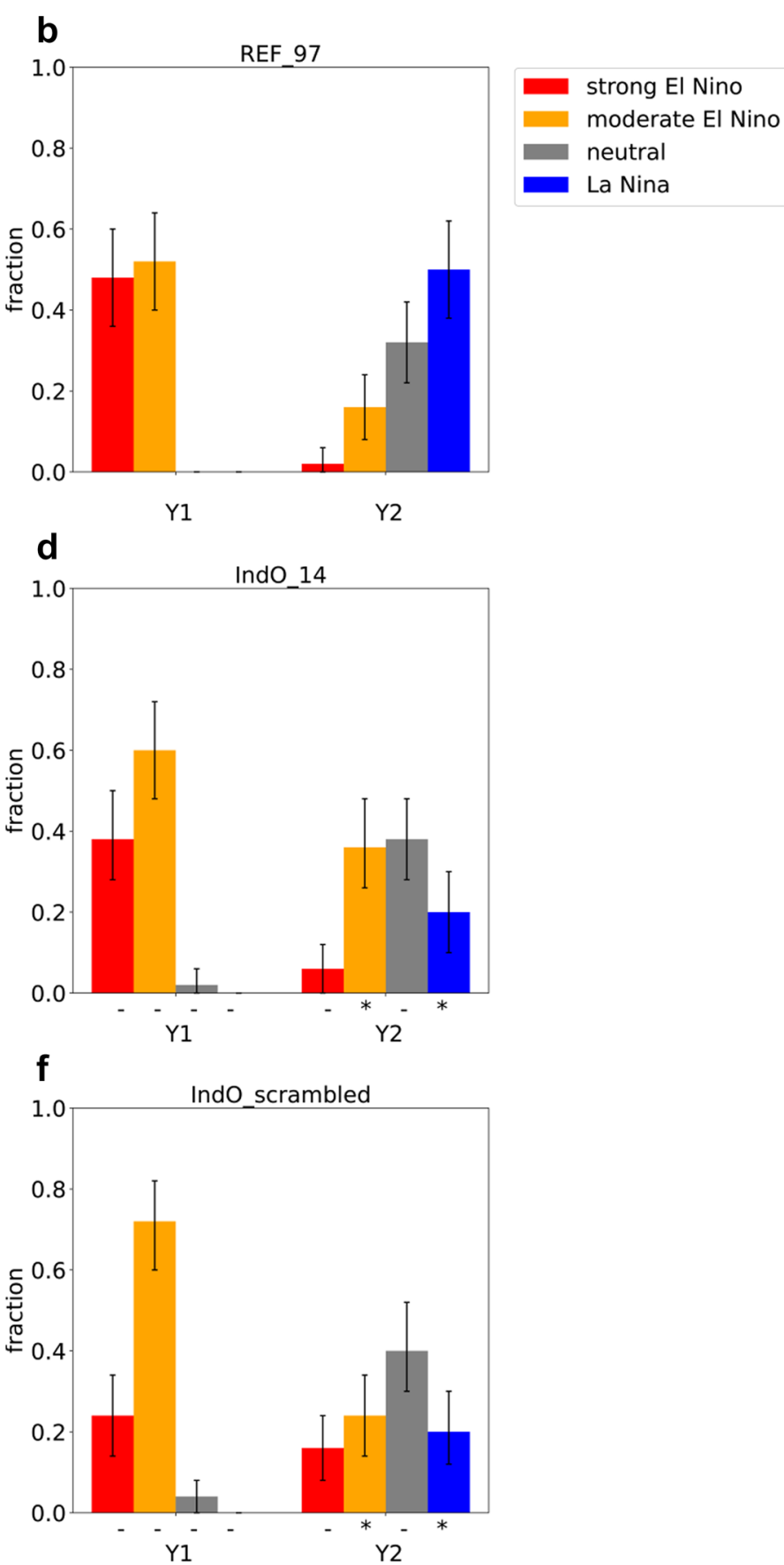

Fig. 5 Probability of occurrence of ENSO events in a REF_14, b REF_97, c IndO_97, d IndO_14, e IndO_97sfc, and f IndO_ scrambled in year 1 (Y1) and year 2 (Y2), as derived from counting ensemble members. Bars represent probabilities of La Niña $(\mathrm{N} 3.4<0.5 \mathrm{~K})$, neutral $(-0.5 \leq \mathrm{N} 3.4 \leq 0.5)$, moderate El Niño $(0.5 \mathrm{~K}<\mathrm{N} 3.4<1.8 \mathrm{~K})$, and strong El Niño (N3.4>1.8 K) events. Shown are medians (bars) as well as $5 \%$ and $95 \%$ quantiles (whisk-

compared to 28\% in IndO_97, in exchange for a reduced probability of neutral conditions), and coincides with (in terms of OHC) warmer Pacific conditions in IndO_97sfc compared to IndO_97 (compare Fig. 3b, f). From the results ers) of the probabilities, estimated from 1000 bootstrapped 50-members subsamples of the original ensembles. Stars denote statistically significant changes (90\% confidence level) relative to REF_14 for the Batch_14 experiments (IndO_97, IndO_97sfc, IndO_scrambled) and relative to REF_97 for IndO_14, respectively (estimated from the 1000 probability differences of the 1000 subsamples)

shown so far we cannot rule out that differences in atmospheric teleconnections arising from differing strength of the IOD (despite their by design similar Indian Ocean surface; compare Fig. 3a, e) contributed to the Y2 OHC difference 
between IndO_97 and IndO_97sfc (Izumo et al. 2010). However, we will demonstrate with the ocean heat budget analysis in Sect. 3.2 that the Y2 OHC difference between the two experiments is communicated through the oceanic tunnel.

To put the so far discussed impact of Indian Ocean conditions on ENSO probabilities into context, the probabilities of IndO_scrambled are presented in Fig. 5f. Probability changes in Y1 compared to REF_14 are insignificant, but probabilities in Y2 are similar to those in IndO_97, i.e. there is a similar shift towards increased probability of La Niña. These results indicate that the state of the Indian Ocean in 1997 was highly anomalous in the sense that it strongly enhanced the likelihood of a strong El Niño in Y1, making the outcome of IndO_97 quite extreme compared to REF_14 and IndO_scrambled-an impact likely communicated through the atmospheric bridge, as the similarity of IndO_97 and IndO_97sfc suggests. In contrast, the general similarity of Y2 ENSO probabilities in IndO_scrambled and IndO_97 in conjunction with the significantly lower probability of La Niña in REF_14 suggests that the Indian Ocean in 2014 and its impact on the Pacific through the oceanic tunnel (to be corroborated in Sect. 3.2) was highly anomalous as well, albeit in a different direction than in 1997.

Experiments from Batch_97 further confirm the findings above. There is a shift of ENSO probabilities after changing Indian Ocean initial conditions. In Y1, the probability of a strong El Niño decreases from 48\% in REF_97 (Fig. 5b) to 38\% in IndO_14 (Fig. 5d). The differences are more noticeable in Y2, when REF_97 has probabilities of 18\% (50\%) for at least moderate El Niño (La Niña), while IndO_14 has probabilities of $42 \%$ (20\%) for El Niño (La Niña), which actually represents a stronger shift in probabilities than in the Batch_14 experiments. We note that probabilities in AllO_97 are very similar to those in REF_97 (not shown).

The contrasting behaviour between the forecasts in 2014 and 1997 can be summarized by considering the joint forecast probabilities in Y1 and Y2. The probability of a strong warm event occurring within the two years is $31 \%$ in REF_14 and 49\% in REF_97, of which the probability of that event occurring in $\mathrm{Y} 1$ is $53 \%$ in REF_14, substantially lower than the 96\% in REF_97.

The Indian Ocean initial conditions also affect the Y1 and Y2 spread of the SST forecast Niño 3.4 and SETIO, which is discussed in more detail in the supplementary material S4. In short, results from all experiments using Indian Ocean initial conditions from 1997 show generally higher SST spread in SETIO and subsequently also in Niño 3.4. This suggests that the Indian Ocean conditions in 2014 were rather stable compared to 1997 and not susceptible to perturbations, which acted to damp instabilities and consequently spread. The comparatively low spread in experiments using 2014 Indian Ocean conditions also suggest that the nonoccurrence of an IOD event in 2014 was highly predictable, but the occurrence of the event (favoured with 1997 Indian Ocean conditions), is less predictable. The dependence of Niño 3.4 spread on Indian Ocean conditions demonstrates that the latter can play a role in ENSO predictability, in addition to changes in the Pacific itself (Hu et al. 2020).

\subsection{Role of Indian Ocean in the energy budget of tropical Pacific}

We now complement the dynamical analysis above with an examination of the heat budgets diagnosed from the experiments. This aims at confirming the observational finding by Mayer et al. (2018) that the weak OHC loss in 2014/15 can be explained by the anomalous ocean heat convergence associated with the unprecedentedly weak ITF, and that the state of the Indian Ocean played a dominant role. Moreover, changes to the Pacific heat budget will also help to better understand changes in SSTs and ENSO probabilities discussed in the previous sections. We begin with a detailed discussion of the budgets of the main experiments from Batch_14 and then present changes in the heat budgets of the remaining experiments in a more condensed way.

\subsubsection{Predicting the tropical Pacific energy balance in 2014-2016 - role of the Indian Ocean}

Here we investigate how the Indian Ocean state contributed to the energy budget of the tropical Pacific during the 2014-2016 period, and which terms played a dominant role. We confirm the ITF as a key player in the differences between experiments, which we further corroborate using the sensitivity experiments. Furthermore, we analyse the ability of the model to predict the tropical Pacific energy budget, as well as the degree of predictability of the tropical Pacific energy budget in comparison with the prediction of SST.

The time evolution during 2014-2016 of the different terms contributing to the tropical Pacific ocean heat budget anomalies is presented in Fig. 6 for the main experiments of Batch_14 (REF_14, IndO_97 and AllO_97). Shown are: (a) full-depth $\mathrm{OHC}$, (b) contribution from accumulated net surface energy flux, (c) contribution from accumulated ocean heat convergence, and (d) accumulated ITF volume flux. Figure 6a shows neutral $\mathrm{OHC}$ anomaly evolution in REF_14 for the two-year period. The $\mathrm{OHC}$ evolution is a result of anomalous net surface energy loss of the ocean to the atmosphere (Fig. 6b) and heat gain through anomalous ocean heat convergence (Fig. 6c) balancing each other (compare Eq. 1). Figure 6d shows that REF_14 exhibits a reduction of ITF volume fluxes $\left(\sim 130,000 \mathrm{~km}^{3}\right.$ over the 2-year period, which corresponds to an average ITF volume flux reduction of $\sim 2.1 \mathrm{~Sv}$ ). This is quantitatively consistent with results from Mayer et al. (2018) based on ocean reanalysis 


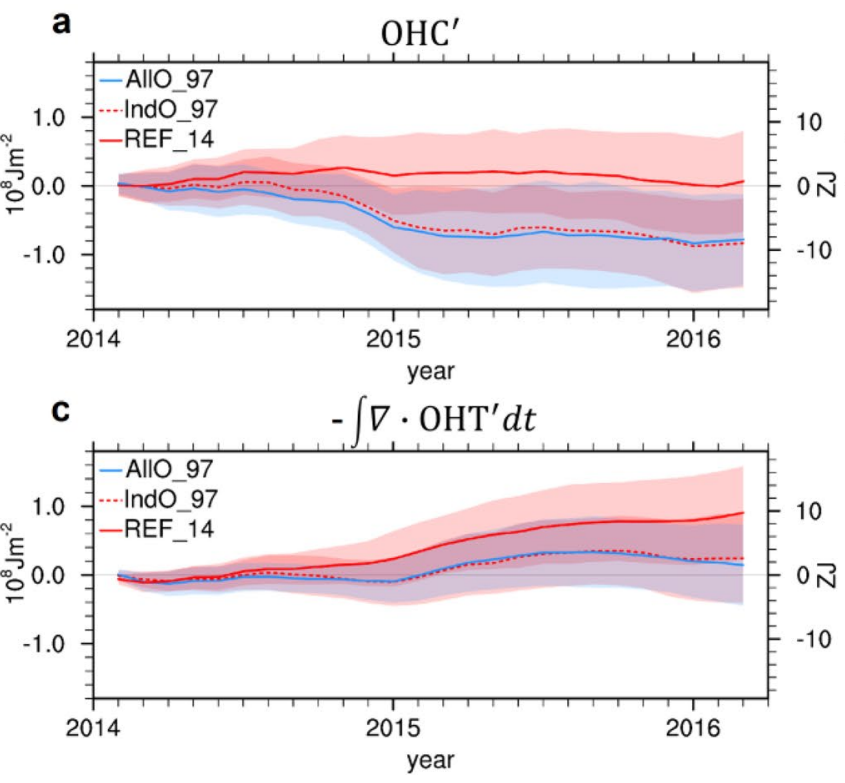

Fig. 6 a Changes in accumulated tropical (30 N-30 S) Pacific OHC' $\left(=\int \mathrm{FS}^{\prime} \mathrm{dt}-\int \nabla \cdot \mathrm{OHT}^{\prime} \mathrm{dt}\right)$ in REF_14, IndO_97, and AllO_97 and contributions to the $\mathrm{OHC}$ changes from $\mathbf{b}$ accumulated net surface energy flux $\left(\mathrm{F}_{\mathrm{S}}{ }^{\prime}\right)$ and $\mathbf{c}$ ocean heat transport convergence $\left(-\mathrm{V} \bullet O H T^{\prime}\right.$; positive means a warming contribution, i.e. ocean heat convergence). Accumulated ITF volume transports ( $\mathrm{ITF}_{\mathrm{vol}}$, positive eastward) are

ORAS5 (see their Fig. 2a). The ITF exports warm water from the west Pacific into the Indian Ocean. Consequently, its reduction explains the anomalous ocean heat convergence for REF_14 seen in Fig. 6c. We note that the existence of a balance between anomalous oceanic surface heat exchange and anomalous ocean heat convergence is consistent with Nieves et al. (2015) and Lee et al. (2015). They found enhanced surface heat uptake and ocean heat divergence (via strengthened ITF) during the hiatus period preceding 2014, while our experiments indicate that the balance is reversed during the 2014-16 period, with weakened ITF, anomalous heat convergence, and consequently anomalous warming of tropical Pacific. This reversal is consistent with the change of phase of the Indo-Pacific decadal variability (Johnson 2016).

Changing Indian Ocean ICs to 1997/02 (IndO_97) leads to a marked shift in the energy budget evolution, as shown by the dashed lines in Fig. 6 (for an illustration of the spatial distribution of the impact see supplementary material S2) There is a basin-average anomalous cooling on the order of $10 \mathrm{e}^{8} \mathrm{~J} \mathrm{~m}^{-2}$ (corresponding to $\sim 10.7 \mathrm{ZJ}$ ) over the 2-year period (Fig. 6a), which is about $50 \%$ of the difference in observed OHC evolution found between the strong 1997/98 $\left(\sim-11.5 \times 10^{8} \mathrm{~J} \mathrm{~m}^{-2}\right)$ and 2015/16 $\left(\sim+9.6 \times 10^{8} \mathrm{~J} \mathrm{~m}^{-2}\right) \mathrm{El}$ Niño events (see Fig. 1b in Mayer et al. 2018). As a measure of signal-to-noise ratio of changes in the $\mathrm{OHC}$, we compute the ratio of ensemble mean difference in tropical Pacific
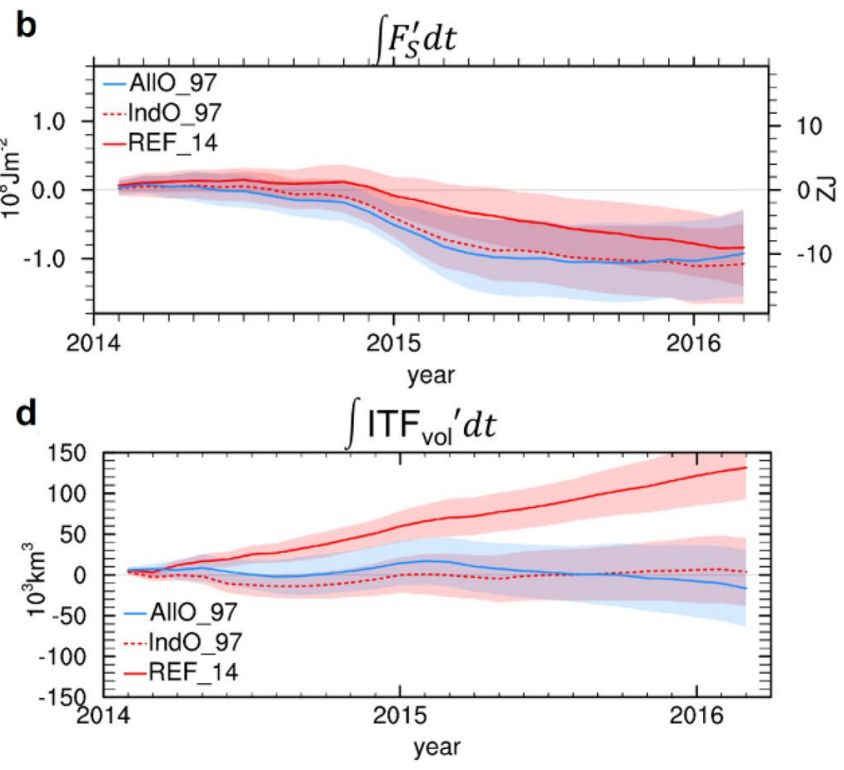

shown in d. All values represent anomalies w.r.t model climatology (estimated from AllO_scrambled). An accumulated energy flux/ change of $10^{8} \mathrm{~J} \mathrm{~m}^{-2}$ corresponds to a mean flux/rate of $1.6 \mathrm{~W} \mathrm{~m} \mathrm{~m}^{-2}$ and an anomalous ITF volume flux accumulation of $10^{5} \mathrm{~km}^{3}$ over two years corresponds to an average volume flux change of $1.6 \mathrm{~Sv}$. The shading represents ensemble spread $( \pm 1 \sigma)$

OHC between IndO_97 and REF_14 and the ensemble spread in REF_14 in Dec 2014 and 2015 (i.e. lead months 11 and 23), as displayed in Fig. 6a. The ratio is $\sim 1.3$ both in Dec 2014 and 2015 (significant on 90\% level based on a two-sided t-test). This can be compared to the signal-tonoise ratio of changes in Niño 3.4 SSTs, which we compute analogously. This ratio is 0.7 for December of $\mathrm{Y} 1$ and 0.5 for December of Y2 (both values statistically significant on the $90 \%$ level), indicating a higher signal-to-noise ratio for OHC changes than for Niño 3.4 SSTs.

The negative OHC anomaly in IndO_97 end of Y2 stems almost entirely from a different behaviour of anomalous ocean heat convergence in IndO_97 compared to REF_14 (Fig. 6c). The anomalous ocean heat convergence seen in REF_14 is not present in IndO_97. This difference is attributed to the strongly reduced ITF volume flux in REF_14 (Fig. 6d), contributing positively to the ocean heat convergence, while the ITF shows neutral anomalies in IndO_97.

Although the two-year accumulated surface energy flux anomalies are similar between REF_14 and IndO_97 (Fig. 6b), the experiments differ in the relative values of $\mathrm{Y} 1$ and Y2, with IndO_97 exhibiting a stronger cooling during $\mathrm{Y} 1$ and a weaker cooling during Y2. These interim differences can be explained by warmer SST anomalies in Y1 and colder SST anomalies in Y2 in IndO_97 compared to REF_14 (compare Fig. 4a). 
Figures 6a-d also show results for AllO_97, where ocean ICs have been replaced with values from 1997/02 globally. The results for the heat budget terms and ITF volume fluxes are overall very similar to IndO_97. This indicates that the Indian Ocean initial conditions in 2014 had a strong control on the ITF evolution and tropical Pacific OHC for the subsequent 2 years. The difference in Pacific Ocean initial conditions 2014 and 1997 play much a smaller role in the 2 year incremental changes of the energy budget. Please note that this not the case in general, as Pacific conditions usually are relevant in determining the strength of the ITF via zonal winds and western Pacific sea level (e.g., England and Huang 2005; Mayer et al. 2014, 2018), but these drivers obviously play a minor role due to the extreme nature of our experiments.

\subsubsection{Tropical Pacific energy budget forecast sensitivity}

We now address how unusual the 2014 sensitivities of the tropical Pacific energy budget were by comparing with the results from Batch_97 and the sensitivity experiment IndO_scrambled. Moreover, results from Batch_97 help to understand how linear the sensitivity of the heat budget to Indian Ocean initial conditions is, since Batch_97 experiments represent a mirrored setup as those from Batch_14. Furthermore, we include results from IndO_97sfc to quantify the impact of the atmospheric bridge versus the oceanic tunnel in the energy budget. The results are summarized in Fig. 7 for $\mathrm{Y} 1$ and $\mathrm{Y} 2$.

Results show that in Y1, in contrast with REF_14 (shown in Fig. 7a and Fig. 6a), REF_97 (Fig. 7b) exhibits strong $\mathrm{OHC}$ loss in the tropical Pacific, which is mainly driven by net surface heat flux anomalies associated with the simulated El Niño event in Y1. The ocean heat convergence anomalies of REF_97 in Y1 are small and ITF volume flux anomalies are close to neutral, i.e. all very similar to AllO_97 in Y1 (see Fig. 6). IndO_14 exhibits a much weaker OHC loss in Y1 than REF_97, which is mainly due to enhanced ocean heat convergence compared to REF_97, associated with a reduced ITF volume flux in Y1 compared to REF_97. IndO_14 (Fig. 7d) exhibits very similar $\mathrm{OHC}$ evolution in Y1 as REF_14 (Fig. 7a) and AllO_14 (not shown). Results for Y2 show that the ITF and heat convergence terms are cumulative in the experiments initialized with 2014 Indian Ocean conditions, i.e. their magnitude is enhanced in Y2 w.r.t Y1. In contrast, experiments with 1997 Indian Ocean show small and insignificant contributions from ITF and $-\nabla \cdot$ OHT in both years. The Y2 cumulative surface flux contribution is negative in all experiments, since all of them forecast positive N3.4 anomalies during most of the twoyear interval, but its magnitude is smallest in experiments REF_14 (Fig. 7a) and AllO_14 (not shown), which consequently have smaller surface heat loss in Y1.
The reversed sensitivity to the Indian Ocean initial conditions of Batch_97 compared to Batch_14 (IndO_14 vs. REF_97 represents a mirrored version of IndO_97 vs. REF_14) thus demonstrates the robustness of the response, and indicate that the impact of the Indian Ocean states on the ITF and ocean heat convergence are not limited to the state of the tropical Pacific in 2014. This fact is not inconsistent with basin-wide heat budget evolution being driven by large scale differences between the states of the Indian and Pacific oceans which affect the zonal pressure gradients across the Indo-Pacific Warm Pool, and in turn drive exchanges via the ITF (Yamagata et al. 1996; Meyers 1996; Mayer et al. 2018; Pujiana et al. 2019). Rather, the similarities between the OHC evolution of AllO_14 and IndO_14 (which differed in the Tropical Pacific initial conditions) suggests that the Tropical Pacific state in 1997 and 2014 was quite similar.

Having established that the independence of the Indian Ocean response to the Pacific state, we evaluate if the dominant role of the Indian Ocean in the Tropical Pacific heat budget evolution is specific to 2014 and 1997. The heat budget for IndO_scrambled (Fig. 7f) shows moderate OHC loss that lies in between that of REF_14 and IndO_97 or, more generally, between experiments with 2014 and experiments with 1997 Indian Ocean initial conditions. Similar to the other experiments, the differences in anomalous OHC evolution compared to REF_14 arise from differences in anomalous ocean heat convergence rather than from accumulated surface flux anomalies. The relationship between ocean heat convergence and ITF volume fluxes is further corroborated by the fact that the moderately positive volume flux anomalies in IndO_scrambled lie in between those of REF_14 and those of IndO_97. This suggests that the Indian Ocean conditions in 2014 that yielded the extreme ITF volume flux reduction during 2014-16 (both in REF_14 and reanalyses) were indeed anomalous: the ensemble mean values for the ITF in REF_14 (as well as that of IndO_97sfe, and IndO_14) lie on the upper range of the spread in IndO_scrambled. In contrast, experiments that use Indian Ocean subsurface conditions from 1997 (i.e. IndO_97, REF_97, AllO_97) lie in the lower range of the spread in IndO_scrambled, suggesting that the Indian Ocean in 1997 was also anomalous, but on the opposite side than in 2014. We note that the spread for ITF volume fluxes is markedly enhanced (almost doubled compared to REF_14), confirming the strong constraint of the Indian Ocean conditions on ITF strength.

Finally, we try to find out if the heat budget differences discussed above are communicated to the Pacific via the atmospheric bridge or oceanic tunnel. For this we analyse the heat balance terms in experiment IndO_97sfc (Fig. 7e), where only the upper Indian Ocean ICs (upper $\sim 50 \mathrm{~m}$ ) have been replaced with values from 1997/02 (in contrast to IndO_97, where the full-depth Indian Ocean was 

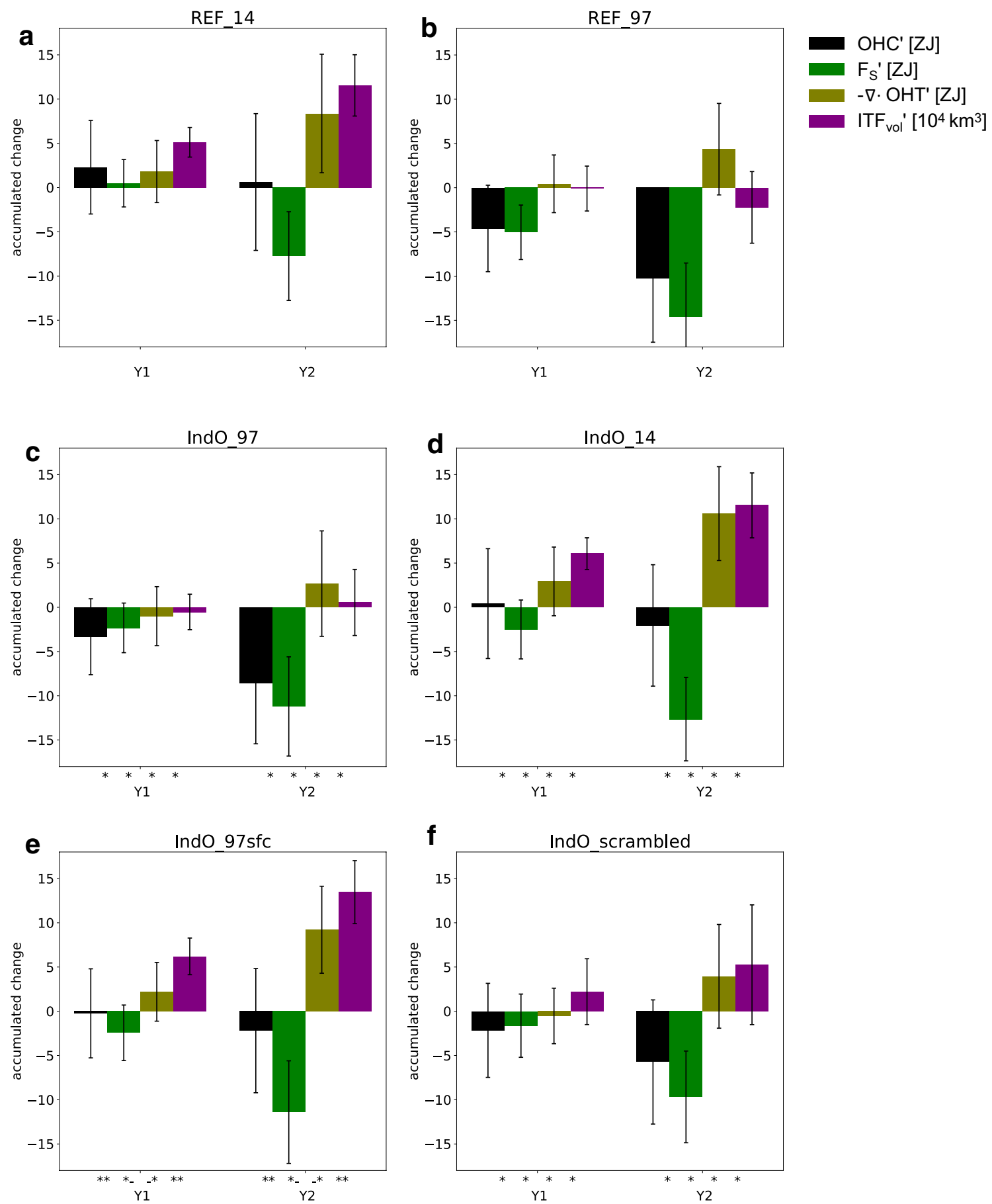

Fig. 7 Accumulated changes in tropical (30 N-30 S) Pacific OHC' $\left(=\int \mathrm{FS}^{\prime} \mathrm{dt}-\int \nabla \cdot \mathrm{OHT}^{\prime} \mathrm{dt}\right.$; in $\left.\mathrm{ZJ}\right)$ and contributions to the $\mathrm{OHC}$ changes from $b$ ) accumulated net surface energy flux $\left(\mathrm{F}_{\mathrm{S}}{ }^{\prime}\right)$ and $\mathrm{c}$ ) ocean heat transport convergence $\left(-\nabla \bullet O H T^{\prime}\right.$; positive means a warming contribution, i.e. ocean heat convergence) in a REF_14, b REF_97, c IndO_97, d IndO_14, e IndO_97sfc, and f IndO_Scrambled end of year 1 (Y1) and year 2 (Y2). Accumulated ITF volume transports (positive eastward; in $10^{4} \mathrm{~km}^{3}$ ) are shown as well. All val-

replaced). The heat budget evolution in IndO_97sfc is overall very similar to REF_14, especially that of ocean ues represent ensemble mean anomalies w.r.t model climatology (estimated from AllO_scrambled). The whiskers represent ensemble spread $( \pm 1 \sigma)$. Stars denote statistically significant changes $(90 \%$ confidence level) relative to REF_14 for the Batch_14 experiments and relative to REF_97 for the Batch_97 experiments, respectively (based on a two-sided t-test). IndO_97_sfc additionally indicates significant changes w.r.t. IndO_97

heat convergence and ITF volume flux. This suggests that it is the Indian Ocean sub-surface that drives the ITF and 
subsequent heat budget changes in IndO_97 compared to REF_14. It thus seems that the Pacific basin-wide heat budget signal discussed above is communicated through the oceanic tunnel and confirms that the sea level gradient across the Warm Pool drives the ITF. However, as has already been seen, e.g., from Fig. 3a, e, the difference between IndO_97sfc and IndO_97 is not as clear when considering SSTs.

\subsection{The relative role of the oceanic tunnel and atmospheric bridge in year-2 ENSO predictability}

In this section, we further explore the question of the Influence of the Indian Ocean in the Y2 ENSO predictability, in particular the relative roles of the oceanic tunnel versus atmospheric bridge. So far we found that in 2014, the atmospheric bridge is responsible for reduced probability of a strong warming in Y1, which inhibits tropical Pacific Ocean heat discharge, favouring the development of a warm event in Y2. On the other hand, the warm Indian Ocean subsurface in 2014 also contributes to high $\mathrm{OHC}$ in the tropical Pacific via reduction of the ITF and associated positive heat convergence anomalies, which also favours development of a warm event in Y2. The atmospheric bridge impact in Y2 is likely more unpredictable, since it depends on the occurrence or non-occurrence of a strong El Niño in Y1. The predictability of the oceanic tunnel mechanism depends on whether the strength of the signal in the initial conditions is strong enough to persist into $\mathrm{Y} 2$ without being masked by the variability of the events in Y1. To gain insight into these questions, we perform intra-ensemble diagnostics to examine the relationship between various budget terms and the ENSO state at the end of Y2. To further inspect the impact of the oceanic tunnel, we cluster the experiments into those with weak ITF (all members from REF_14, IndO_14, AllO_14) and those with strong ITF (all members from REF_97, IndO_97, AllO_97; compare accumulated ITF volume fluxes shown in Fig. 7). We first analyse the OHC (and associated components) as a precursor of ENSO in Y2 (Sect. 3.3.1). In Sect. 3.3.2 we discuss how the amplitude of the Indian-Ocean induced ITF anomalies compare with the possible range of ENSO scenarios during Y1.

\subsubsection{Precursors of ENSO in year 2}

We first assess tropical Pacific OHC as a traditional precursor of ENSO. It is phase-shifted with equatorial SST anomalies and tends to peak 5-6 months before El Niño peaks (Cheng et al. 2019). Thus, we can assume that ensemble members that accumulate more anomalous $\mathrm{OHC}$ from February Y1 to July Y2 (lead month 18 of the forecast is July of Y2) will tend to exhibit a warmer ENSO state at the end of
Y2 than the ensemble members accumulating less anomalous OHC over the first 18 months.

Figure 8 shows scatter diagrams of N3.4 SST anomalies in Dec Y2 (month 23 into the forecasts, $\mathrm{X}$-axis) versus the change in Tropical Pacific OHC (20 N-20 S) accumulated in the preceding months (lead month 1 to 18 , Fig. 8a, y-axis), as well as the terms contributing to these $\mathrm{OHC}$ changes, i.e. surface heat exchange (Fig. 8b) and ocean heat convergence (Fig. 8c), also accumulated over the first 18 months of the forecast. Both the "weak ITF" subsample (black crosses) and "strong ITF" subsample (red circles) are shown. Figure $8 \mathrm{a}$ shows that there indeed is a positive correlation between OHC changes and subsequent ENSO state, ranging in $r=0.47$ and $r=0.55$ for the sub-samples and attaining $r=0.58$ for the joined sample ( 300 forecasts). The correlation of the six ensemble means is $r=0.83$. Thus, the change in Tropical Pacific OHC in the preceding 18 months appears to be a robust predictor of N3.4 SST in month 23, represented in the individual ensemble members, across subsamples, and the ensemble mean. Note also that the clouds of values between weak and strong ITF appear distinct, in that the weak ITF cases are found mainly in the top right quadrant, corresponding to higher $\mathrm{OHC}$ and higher SST values.

Next, we evaluate how the individual components responsible for the OHC change (surface exchange in Fig. 8b and ocean heat convergence in Fig. 8c) contribute to the found relationship. Both surface fluxes and ocean heat convergence drive OHC changes in the same direction, as the sign of the relatively high correlations for both terms indicate, with ocean heat convergence $(r=0.32$ and $r=0.41$ for the two sub-samples; $r=0.46$ for the joined sample; $r=0.57$ for the ensemble means) showing similar correlation as the accumulated net surface flux $(r=0.34$ and $r=0.39$ for the two sub-samples; $r=0.43$ for the joined sample; $r=0.96$ for the ensemble means) when considering the full ensembles. The high correlation of the accumulated net surface heat flux can be interpreted as a clear signal that the net heat loss associated with a warm event in Y1 precludes the occurrence of another warm event in Y2.

The relationship between accumulated ITF volume flux and Niño 3.4 in December of Y2 is shown in Fig. 8d. The weak and strong ITF samples appear distinct, both in the values of accumulated ITF (by definition of the sub-samples) and the values of SST. For the sub-samples, there is only a weak relationship between preceding ITF strength and ENSO in Y2, with correlations of 0.12 and 0.18 for the "strong ITF" and "weak ITF" sub-sample, respectively, while the correlation of the joined sample is larger $(r=0.36)$. The lower correlation of the preceding ITF volume flux with Niño 3.4 in December of Y2, compared with the values of ocean heat convergence (Fig. 8c) are expected as the intra-ensemble variability of the ITF is mainly driven by intra-ensemble variability 
a

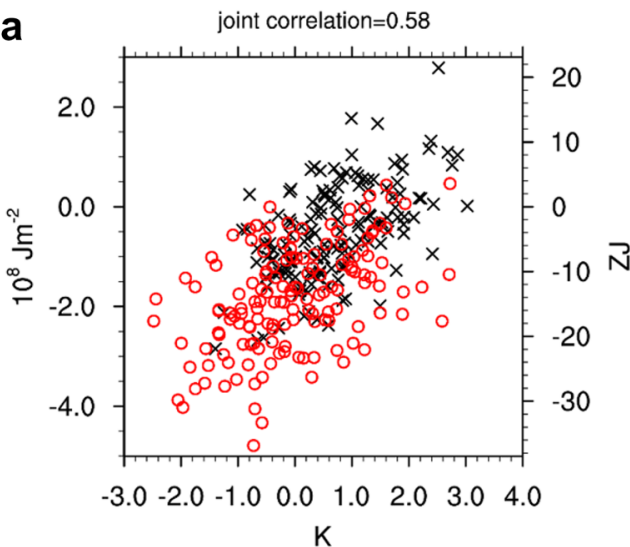

$X$ 'weak ITF' N3.4 Y2 vs. month 1-18 OHC' ( $r=0.55)$

$\circ$ 'strong ITF' N3.4 Y2 vs. month 1-18 OHC' ( $r=0.47)$

C

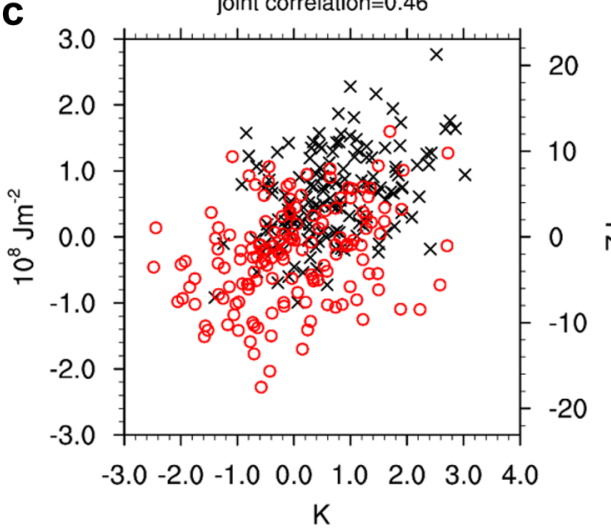

$\times$ 'weak ITF' N3.4 Y2 vs. month $1-18-\nabla \cdot$ OHT' $^{\prime}(r=0.41)$

$\circ$ 'strong ITF' N3.4 Y2 vs. month $1-18-\nabla \cdot \mathrm{OHT}^{\prime}(\mathrm{r}=0.32)$

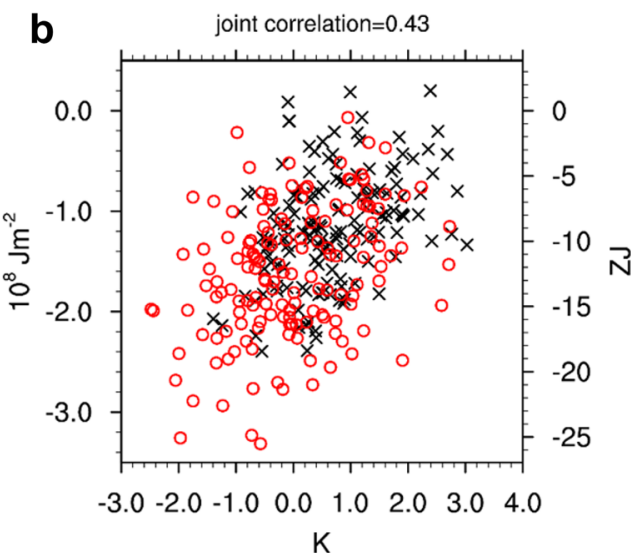

$\times$ 'weak ITF' N3.4 Y2 vs. month 1-18 $F_{S}$ ' $(r=0.39)$

0 'strong ITF' N3.4 Y2 vs. month 1-18 $F_{S}$ ' $(r=0.34)$

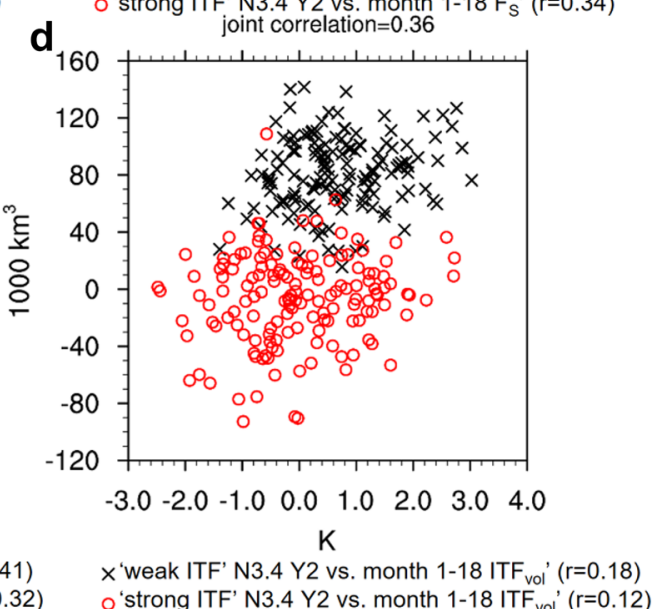

Fig. 8 Different heat budget terms as predictors of N3.4 in December of Year 2. Predictors are the accumulated contribution from February-Y1 to July-Y2 to the Tropical Pacific (20 N-20 S) heat budget: a $\mathrm{OHC}$, b net surface heat flux, c) ocean heat convergence and d) ITF volume flux. "Weak ITF" sample consists of REF_14, IndO_14, and AllO_14. "Strong ITF" sample consists of REF_97, IndO_97, and

associated with ENSO. As will be shown more explicitly below, the contribution of the ENSO-driven ITF response to the ocean heat convergence is in opposite direction as the more dominant meridional heat discharge/recharge (as suggested by the higher correlation seen with $-\nabla \bullet O H T$ in Fig. 8c) and also in opposite direction as the surface heat exchange. The low correlations of the individual ensemble members are in contrast with the high correlation between the six ensemble means $(0.79$, a high value consistent with the results in Figs. 6 and 7). The high correlation of the ensemble means suggests that, although the intra-ensemble variability of ITF volume fluxes (i.e. the unpredictable component) is unrelated to the subsequent ENSO state (hence the low correlation for the subsamples), the predictable component of the ITF is indeed a good predictor of ENSO in Y2. Moreover, the fact that
AllO_97. Intra-sample correlation coefficients are given in the legend, and the joint correlation is given in the figure titles. An accumulated energy flux/change of $10^{8} \mathrm{~J} \mathrm{~m}^{-2}$ over 18 months corresponds to a mean flux/rate of $2.1 \mathrm{~W} \mathrm{~m}^{-2}$ and an anomalous ITF volume flux accumulation of $10^{5} \mathrm{~km}^{3}$ over 18 months corresponds to an average volume flux change of $2.1 \mathrm{~Sv}$

the two subsamples are clearly separated indicates that the predictable component of the ITF is linked to the Indian Ocean initial conditions (remember that "strong ITF" experiments use 1997 conditions and "weak ITF" experiments use 2014 conditions, respectively). This idea is further explored below.

\subsubsection{Contrasting drivers of ITF variability}

We further examine the contemporaneous intra-sample variability of net surface flux and ITF in relation with temporally averaged Niño 3.4 anomalies (both for the Feburary-Y1 to July-Y2 interval). Figure 9a shows that the accumulated net surface energy flux is strongly anticorrelated with the contemporaneous SST $(r=-0.67$ for the joined sample and $r=-0.66$ for the sub-samples), 


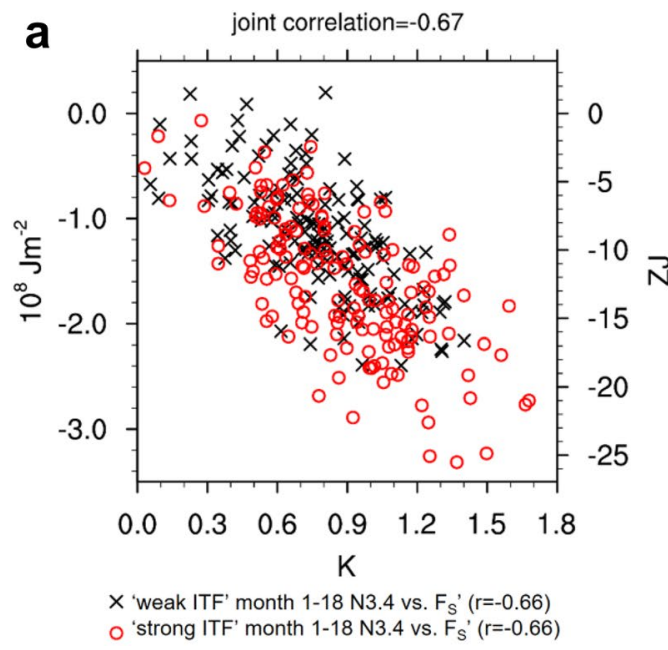

Fig. 9 Scatter diagrams of February-Y1 to July-Y2 averaged N3.4 against February-Y1 to July-Y2 accumulated a net surface flux in the Pacific (20 N-20 S) and b ITF volume flux."Weak ITF" sample consists of REF_14, IndO_14, and AllO_14."Strong ITF" sample

reflecting stronger surface heat loss associated with higher Niño 3.4 values and weaker surface heat loss associated with lower Niño 3.4 values. Thus, higher (lower) SSTs during the first 18 months of the forecast prepare the ground for a cooler (warmer) ENSO state in month 23 (=December of Y2, in Fig. 8b) through the negative surface flux feedback, which increases surface heat loss for warm SST anomalies and reduces surface heat loss for cool SST anomalies (Trenberth et al. 2002; Mayer et al. 2014, 2016; Cheng et al. 2019). This relationship is very similar for both sub-samples, indicating this relationship is independent of the ITF strength.

Figure $9 \mathrm{~b}$ shows the corresponding scatter diagram for the ITF and N3.4 anomalies. There is a clear linear relationship for the sub-samples, with weaker ITF (positive volume flux anomalies) going with warmer SSTs and vice versa. This is consistent with earlier studies finding stronger (weaker) ITF fluxes during La Niña (El Niño) due to changes in the trade winds (England and Huang 2005; Mayer et al. 2014). Weaker ITF (associated with higher Niño 3.4 values) acts to retain more warm waters in the tropical Pacific and consequently reduces OHC discharge during El Niño. The opposite is the case for stronger ITF associated with lower Niño 3.4 values. This relationship could thus be viewed as a positive feedback to ENSO.

An outstanding feature of Fig. $9 \mathrm{~b}$ is the offset of the two sub-samples, determined by the Indian Ocean initial conditions, which is larger than the internal variability among ensemble members. This clear separation indicates the dominant and long-lasting influence of the Indian Ocean initial state, which affects inter-basin sea level gradients, and is independent of the intra-sample Niño3.4 variability,

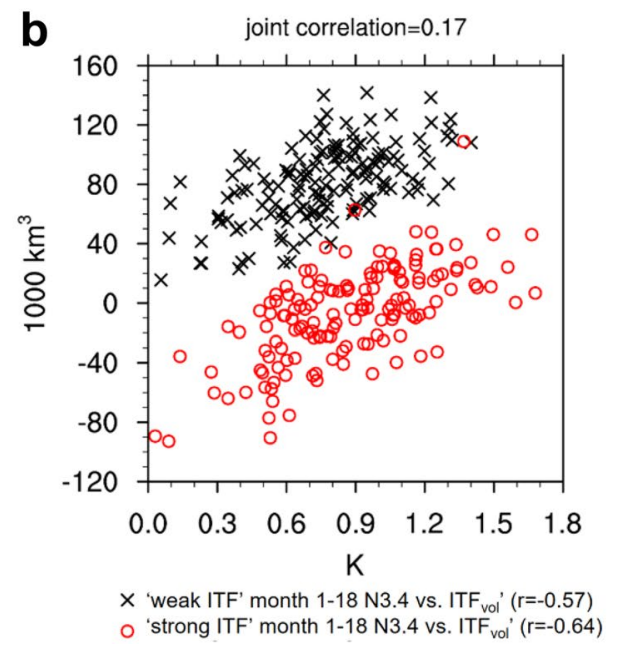

consists of REF_97, IndO_97, and AllO_97. Intra-sample correlation is given in the legend, and the joint correlation is given in the figure titles

which occurs on top of this offset. We quantify the relative importance of ENSO conditions and the inter-basin sea level gradient by comparing the intra-cluster spread (as a measure for the former) and inter-cluster mean difference (as a measure for the latter) in Fig. 9b. The intra-cluster spread is $25.7 \times 10^{3} \mathrm{~km}^{3}$ (or $\sim 0.5 \mathrm{~Sv}$ over 18 months) and $31.7 \times 10^{3} \mathrm{~km}^{3}$ (or $\sim 0.7 \mathrm{~Sv}$ ) for the weak and strong ITF cluster, respectively, while the inter-cluster mean difference is substantially larger and attains $87.7 \times 10^{3} \mathrm{~km}^{3}$ (or $\sim 1.9 \mathrm{~Sv}$ ).

This result helps to understand the substantially increased correlation found for the joined sample in Fig. 8d: for the"strong ITF" sub-sample, there is stronger export of Pacific warm waters and associated Pacific OHC loss owing to the Indian Ocean initial conditions (and quite independent of the intra-sample variability associated with Niño 3.4). This favours cooler ENSO conditions in Y2. In contrast, the"weak ITF" sub-sample retains more warm water in the Pacific and thus favours warmer ENSO conditions in Y2. The influence of the Indian Ocean initial conditions lasts into the forecast, and the ITF values of the two subsamples remain clearly different in spite of the intra-ensemble variability due to ENSO. The comparatively large inter-cluster difference demonstrates the importance of the background conditions for the ITF strength, and explains their stronger impact on ENSO. This finding is illustrated by the histogram in Fig. 10, which shows the marked shift towards cooler N3.4 values in the "strong ITF" sub-sample in Y2. 


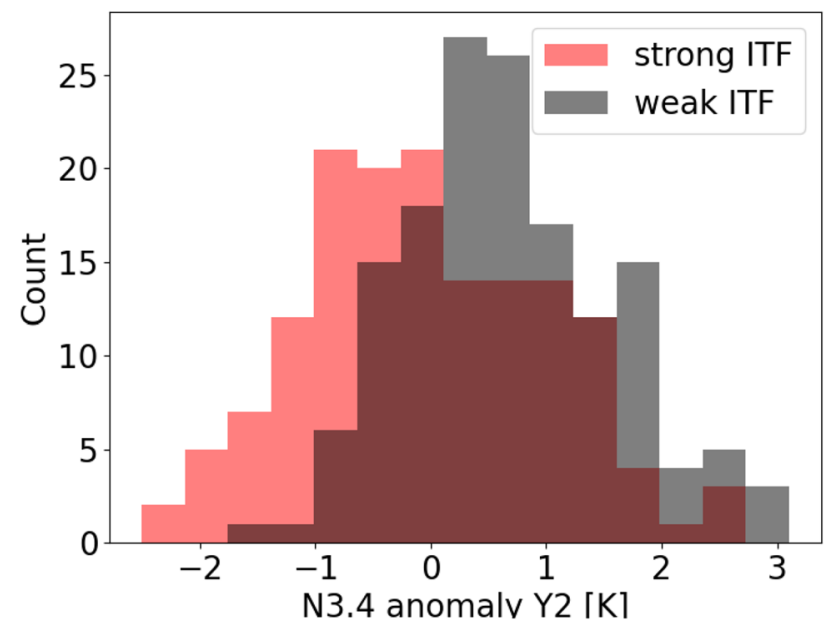

Fig. 10 Histogram showing the distribution of N3.4 anomalies end of year 2 (=lead month 23) in the two "strong ITF" and "weak ITF" subsamples. Counts were obtained from the 150 ensemble members contained in each subsample

\section{Synthesis and conclusions}

Following up on the findings by Mayer et al. (2018), who reported the role of the anomalously weak ITF in the energy budget of the tropical Pacific during 2015/16 El Niño, we investigated whether this anomalous ITF event was predictable, and we tested their hypothesis regarding the key role of the Indian Ocean state in controlling the strength of the ITF in this particular event. We also explored the role that the Indian Ocean state may have in the occurrence of extreme El Niño events. A set of 25-months-long coupled forecasts initialized in Feb 1997 and Feb 2014, in which the Indian Ocean initial conditions have been altered, formed the basis of this study.

Results for the two-year-long forecast experiments clearly demonstrate that the anomalously weak ITF in 2014-2016 was predictable with a strong signal-to-noise ratio, and so was its influence on the Tropical Pacific OHC. Experiments with altered Indian Ocean initial conditions reveal the dominant and long-lasting role of the Indian Ocean Initial conditions in controlling the intensity of the ITF, which in return affects ocean heat convergence and $\mathrm{OHC}$. The model results confirm that the surprisingly absent $\mathrm{OHC}$ discharge found in reanalyses during the 2015/16 El Niño was indeed related to the anomalously warm Indian Ocean conditions during this time, as speculated by Mayer et al. (2018). It has also been demonstrated that this long memory is associated with the subsurface of the Indian Ocean (below $50 \mathrm{~m}$ ). Moreover, when compared with forecasts initialized with Indian Ocean Initial conditions from different years, the 2014 (1997) Indian Ocean initial conditions produce ITF anomalies at the limits of the $\pm 1 \sigma$ range, demonstrating that the Indian Ocean state was highly anomalous in these two years, albeit in opposite directions. Changing the Indian Ocean between 2014 and 1997 yields much larger differences in ITF transports and two-yearly Pacific evolution than exchanging Pacific conditions between 2014 and 1997. This shows that i) the inter-basin sea level gradient determines the strength of the ITF (as Mayer et al. 2018 already found for reanalysis data) and inter-basin heat exchanges and ii) the Western Pacific conditions in 2014 were similar to 1997 (as can be seen qualitatively already from Fig. 1). The Indian Ocean control on the ITF appears as a distinctively different mechanism in addition to the well-known control exerted by ENSO (weaker ITF transports during El Niño, stronger ITF transports during La Niña). In fact, the impact of changed background conditions on ITF strength is at least as strong as the impact seen from Niño 3.4 anomalies in a range of $\sim 2 \mathrm{~K}$.

The state of the Indian Ocean played an important role in conditioning the probability of extreme ENSO events in 1997-1999 and 2014-2016. The intensity of the Pacific warming in year 1 of the forecast (Y1) appears connected with the occurrence of a positive IOD event, which is much favoured by the 1997 Indian Ocean state, and predictably absent with 2014 Indian Ocean conditions. As suggested by the results from the experiment where only the Indian Ocean surface was perturbed, the influence in $\mathrm{Y} 1$ is via the atmospheric bridge, consistent with earlier findings of, e.g., Behera and Yamagata (2003), Luo et al. (2010) or Annamalai et al. (2010). However, the Indian Ocean subsurface conditions also influence the intensity and duration of the IOD event in Y1. These results are consistent with Cai et al. (2019), who confirm the role of positive IOD events in reinforcing El Niño events, but also emphasize that the basin-wide Indian Ocean warming acts to damp El Niño development. The latter is seen, e.g., in REF_14 relative to IndO_97, but as the magnitude of the Indian Ocean Dipole mode turned out to be much more distinct in our experiment than that of the basinwide mode, we refrain from inferring strong conclusions about the potentially important role of the latter. The influence of the Indian Ocean subsurface is more visible in the second year of the forecasts (Y2), affecting the whole Indo-Pacific coupled system. When using 1997 initial conditions in the Indian Ocean, the persistent $\mathrm{OHC}$ deficit favours the occurrence of a second positive IOD in $\mathrm{Y} 2$, but the dominant effect is the pre-conditioning of the Pacific OHC through anomalous ocean heat transports associated with an enhanced ITF. With 1997 (2014) Indian Ocean conditions, anomalously strong (weak) ITF leads to loss (retention) of $\mathrm{OHC}$ through oceanic transports, which consequently increases (decreases) the probability of a $\mathrm{La}$ Niña event in the second year. Another important result in this context is that the predictable component of the ITF, i.e. changes arising from changed sub-surface conditions in the Indian Ocean, is a good predictor of ENSO in Y2. In 
contrast, the unpredictable component of the ITF, i.e. variations arising largely from winds varying with concurrent ENSO conditions, is only weakly related with subsequent ENSO states. Despite these intriguing results we do not preclude that the atmospheric bridge plays a role in $\mathrm{Y} 2$ as well, as suggested by Izumo et al. (2010). Nevertheless, the role of the oceanic tunnel in ENSO prediction appears underappreciated in the literature so far and merits further investigation.

A specific conclusion from this study is that if in 2014 the Indian Ocean state would have been comparable to that of 1997, it would have been more likely to have a strong El Niño event in 2014, and more likely to have a La Niña event in 2015. This is consistent with Dong and McPhaden (2018), who attributed the arrested development of the 2014 El Nino to the anomalously warm Indian Ocean, which acted to keep atmospheric convection and low-level convergence over the Indian Ocean and thus contributed to easterly wind anomalies in the equatorial Pacific. On the other hand, if in 1997 the Indian Ocean would have been similarly warm as in 2014, the 1997/98 El Niño and 1998/99 La Niña events would likely have been weaker as well as the Pacific OHC loss during that time. From that perspective, the Indian Ocean state is crucial in determining the two-yearly evolution of ENSO conditions, even when Pacific conditions seem favourable for an El Niño event. Overall, these findings highlight the importance of consistently initializing the entire Indo-Pacific basin for near-term predictions.

The results reported here illustrate the relevance of the information provided by the two-year-long predictions. The forecast information in Y2 is not only valuable on its own right, but also aids interpretation of the probabilities in forecasts of Y1, given that the ENSO events in two consecutive years are linked by physical mechanisms. Arguably, in the light of the relatively high probability of a strong El Niño and small probability of a La Niña event in the second year of the 2014 forecasts, forecasters may have assessed the forecast probabilities for Y1 differently and moderated expectation of a strong warm event in 2014/15. Finally, twoyear forecast experiments appear to be a promising test bed to elucidate different mechanisms for understanding crossbasin interaction and the decadal modulation of ENSO.

One caveat of the present study is the use of only one and clearly imperfect model. For example, SEAS5 exhibits a cold bias in the eastern Indian Ocean (Johnson et al. 2019), which possibly degrades the representation of the atmospheric bridge in the operational forecasts. However, the mechanisms found with our arguably extreme experiments are physically plausible and in agreement with earlier works. Nevertheless, it would be desirable to see similar studies using different models.
Supplementary Information The online version contains supplementary material available at https://doi.org/10.1007/s00382-020-05607-6.

Acknowledgements The authors thank two anonymous reviewers for their very useful comments on the manuscript and Chris Roberts (ECMWF) for discussion on uncertainty estimates.

Funding Open Access funding provided by University of Vienna. This work was funded by ECMWF and Austrian Science Fund project P33177.

Availability of data and material The data is available from the authors upon request.

Code availability The code for diagnostics is available from the authors upon request.

\section{Compliance with ethical standards}

Conflict of interest The authors declare that they have no conflict of interest.

Open Access This article is licensed under a Creative Commons Attribution 4.0 International License, which permits use, sharing, adaptation, distribution and reproduction in any medium or format, as long as you give appropriate credit to the original author(s) and the source, provide a link to the Creative Commons licence, and indicate if changes were made. The images or other third party material in this article are included in the article's Creative Commons licence, unless indicated otherwise in a credit line to the material. If material is not included in the article's Creative Commons licence and your intended use is not permitted by statutory regulation or exceeds the permitted use, you will need to obtain permission directly from the copyright holder. To view a copy of this licence, visit http://creativecommons.org/licenses/by/4.0/.

\section{References}

Annamalai H, Potemra J, Murtugudde R, McCreary JP (2005) Effect of preconditioning on the extreme climate events in the tropical Indian Ocean. J Clim 18:3450-3469

Annamalai H, Kida S, Hafner J (2010) Potential impact of the tropical Indian Ocean-Indonesian seas on El Niño characteristics. J Clim 23:3933-3952

Behera SK, Yamagata T (2003) Influence of the Indian Ocean dipole on the Southern Oscillation. J Meteorol Soc Jpn Ser II 81:169-177

Cai W et al. (2019) Pantropical climate interactions. Science 363

Cheng L, Trenberth KE, Fasullo JT, Mayer M, Balmaseda M, Zhu J (2019) Evolution of ocean heat content related to ENSO. J Clim 32:3529-3556

Dee DP et al (2011) The ERA-Interim reanalysis: Configuration and performance of the data assimilation system. Q J R Meteorol Soc 137:553-597. https://doi.org/10.1002/qj.828

Dong L, McPhaden MJ (2018) Unusually warm Indian Ocean sea surface temperatures help to arrest development of El Niño in 2014. Sci Rep 8:1-10

England MH, Huang F (2005) On the interannual variability of the Indonesian throughflow and its linkage with ENSO. J Clim 18:1435-1444. https://doi.org/10.1175/JCLI3322.1

Hu S, Fedorov AV (2017) The extreme El Niño of 2015-2016: the role of westerly and easterly wind bursts, and preconditioning 
by the failed 2014 event. Clim Dyn 52:7339-7357. https://doi. org/10.1007/s00382-017-3531-2

Hu Z-Z, Kumar A, Huang B, Zhu J, L'Heureux M, McPhaden MJ, Yu J-Y (2020) The interdecadal shift of ENSO properties in 1999/2000: a review. J Clim 33:4441-4462

Ineson S et al (2018) Predicting El Niño in 2014 and 2015. Sci Rep 8:10733. https://doi.org/10.1038/s41598-018-29130-1

Izumo $\mathrm{T}$ et al (2010) Influence of the state of the Indian Ocean dipole on the following year's El Niño. Nat Geosci 3:168-172

Jin FF (1997) An equatorial ocean recharge paradigm for ENSO. Part I: Conceptual model. J Atmos Sci 54:811-829. https ://doi.org/10.1175/1520-0469(1997)054\%3c0811:AEORP $\mathrm{F} \% 3 \mathrm{e} 2.0 . \mathrm{CO} ; 2$

Johnson GC (2016) Global oceans (in "State of the Climate in 2016"). Bull Am Meteorol Soc 98:Si-S280. https://doi.org/10.1175/2017B AMSStateoftheClimate.1

Johnson SJ et al (2019) SEAS5: the new ECMWF seasonal forecast system. Geosci Model Dev 12:1087-1117

L'Heureux ML et al (2017) Observing and predicting the 2015/16 El Niño. Bull Am Meteorol Soc 98:1363-1382

Lee S-K, Park W, Baringer MO, Gordon AL, Huber B, Liu Y (2015) Pacific origin of the abrupt increase in Indian Ocean heat content during the warming hiatus. Nat Geosci 8:445-449

Levine AF, McPhaden MJ (2016) How the July 2014 easterly wind burst gave the 2015-2016 El Niño a head start. Geophys Res Lett 43:6503-6510

Luo J-J, Zhang R, Behera SK, Masumoto Y, Jin F-F, Lukas R, Yamagata $\mathrm{T}$ (2010) Interaction between El Nino and extreme Indian ocean dipole. J Clim 23:726-742

Mayer M, Haimberger L, Balmaseda MA (2014) On the energy exchange between tropical ocean basins related to ENSO*. J Clim 27:6393-6403. https://doi.org/10.1175/JCLI-D-14-00123.1

Mayer M, Fasullo JT, Trenberth KE, Haimberger L (2016) ENSOdriven energy budget perturbations in observations and CMIP models. Clim Dyn 47:4009-4029

Mayer M, Balmaseda MA, Haimberger L (2018) Unprecedented 2015/16 Indo-Pacific heat transfer speeds up tropical Pacific heat recharge. Geophys Res Lett 45:3274-3284. https://doi. org/10.1002/2018GL077106

McPhaden MJ (2015) Playing hide and seek with El Niño. Nat Clim Change 5:791-795

Meyers G (1996) Variation of Indonesian throughflow and the El NiñoSouthern Oscillation. J Geophys Res Oceans 101:12255-12263

Newman M et al (2016) The Pacific decadal oscillation, revisited. J Clim 29:4399-4427

Newman M, Wittenberg AT, Cheng L, Compo GP, Smith CA (2018) The extreme 2015/16 El Niño, in the context of historical climate variability and change. Bull Am Meteorol Soc 99:S16-S20
Nieves V, Willis JK, Patzert WC (2015) Recent hiatus caused by decadal shift in Indo-Pacific heating. Science 349:532-535

Pujiana K, McPhaden MJ, Gordon AL, Napitu AM (2019) Unprecedented response of Indonesian throughflow to anomalous Indo-Pacific climatic forcing in 2016. J Geophys Res Oceans 124:3737-3754

Puy M et al (2017) Influence of westerly wind events stochasticity on El Niño amplitude: the case of 2014 vs. 2015. Clim Dyn 1-20

Saji NH, Goswami BN, Vinayachandran PN, Yamagata T (1999) A dipole mode in the tropical Indian Ocean. Nature 401:360-363

Schauer U, Beszczynska-Möller A (2009) Problems with estimation and interpretation of oceanic heat transport-conceptual remarks for the case of Fram Strait in the Arctic Ocean. Ocean Sci 5:487-494

Trenberth KE, Zhang Y (2019) Observed interhemispheric meridional heat transports and the role of the indonesian throughflow in the Pacific Ocean. J Clim 32:8523-8536

Trenberth KE, Caron JM, Stepaniak DP, Worley S (2002) Evolution of El Niño-Southern Oscillation and global atmospheric surface temperatures. J Geophys Res Atmos 1984-2012:107

Ummenhofer CC, Biastoch A, Böning CW (2017) Multidecadal Indian Ocean variability linked to the Pacific and implications for preconditioning Indian Ocean dipole events. J Clim 30:1739-1751

Wang H, Kumar A, Murtugudde R, Narapusetty B, Seip KL (2019) Covariations between the Indian Ocean dipole and ENSO: a modeling study. Clim Dyn 53:5743-5761

Yamagata T, Mizuno K, Masumoto Y (1996) Seasonal variations in the equatorial Indian Ocean and their impact on the Lombok throughflow. J Geophys Res Oceans 101:12465-12473

Zhou Q, Duan W, Mu M, Feng R (2015) Influence of positive and negative Indian Ocean dipoles on ENSO via the Indonesian throughflow: results from sensitivity experiments. Adv Atmos Sci 32:783-793

Zhu J, Kumar A, Huang B, Balmaseda MA, Hu Z-Z, Marx L, Kinter JL III (2016) The role of off-equatorial surface temperature anomalies in the 2014 El Niño prediction. Sci Rep 6:1-8

Zuo H, Balmaseda MA, Tietsche S, Mogensen K, Mayer M (2019) The ECMWF operational ensemble reanalysis-analysis system for ocean and sea ice: a description of the system and assessment. Ocean Sci 15:779-808. https://doi.org/10.5194/os-15-779-2019

Publisher's Note Springer Nature remains neutral with regard to jurisdictional claims in published maps and institutional affiliations. 